\title{
APROXIMAÇÕES ENTRE EDUCAÇÃO INTEGRAL E CIÊNCIA, TECNOLOGIA E SOCIEDADE (CTS)
}

\author{
APPROACHES BETWEEN INTEGRAL EDUCATION AND SCIENCE, \\ TECHNOLOGY AND SOCIETY (STS) \\ APROXIMACIONES ENTRE EDUCACIÓN INTEGRAL Y CIENCIA, \\ TECNOLOGÍA Y SOCIEDAD (CTS)
}

\section{Lia Heberlê de Almeida ${ }^{1}$ Jaqueline Moll ${ }^{2}$}

\begin{abstract}
RESUMO
A educação integral e a educação CTS partem do princípio de uma formação cidadã. Neste estudo, buscou-se com o uso da fotografia o desenvolvimento da capacidade de observação, descrição, e criticidade a partir da temática social educação ambiental e produzir um recurso audiovisual com os conceitos construídos pelos alunos, desta forma identificar as aproximações entre educação integral e CTS. Assim, realizamos oficinas pedagógicas sob a ótica CTS,estruturadas nos três momentos pedagógicos de Delizoicov e Angotti (1992) envolvendo os eixos temáticos: Meio Ambiente, Saúde e Sociedade. A abordagem de pesquisa utilizada foi a pesquisa participante de caráter qualitativo e natureza interpretativa. A coleta de dados foi realizada por meio das atividades desenvolvidas nas oficinas, tais como: saídas a campo, ilustrações e atividades práticas.Para as análises utilizamos como embasamento teórico os autores Auler (2007, 2001), Delizoicov (1992), Angotti (1992), Santos e Auler (2011), Bazzo(2001), Freire (1996) e alguns documentos oficiais.A pesquisa mostra que a educação CTS pelo estudo do meio ambiente também considera as relações sociais e as particularidades de cada território, em conformidade com os pressupostos de educação integral, com propostas educativas mais dialógicas, um espaço de estímulo à reflexão do estudante sobre seu papel de cidadão para com os locais por onde vive e circula. Ao final do trabalho foi produzido um recurso audiovisual com os conceitos construídos pelos alunos. A ideia foi contribuir para a conscientização dos problemas da comunidade local, minimizando possíveis tensões desta natureza.
\end{abstract}

PALAVRAS-CHAVE: CTS. Oficinas. Lixo. Meio Ambiente. Cidadania.

\begin{abstract}
The integral education and the CTS education assume the principle of a citizen formation. In this study, the use of photography was sought to develop the capacity of observation, description, and criticality from the social environmental education theme and to produce an audiovisual resource with the concepts constructed by the students, in order to identify the approximations between integral education and CTS. Thus, we carried out pedagogical workshops under the CTS perspective, structured in the three pedagogical moments of Delizoicov and Angotti (1992) involving the thematic axes: Environment, Health and Society. The research approach used was the participant research of qualitative character and

\footnotetext{
${ }^{1}$ Professora da Rede Municipal de Ensino de São Gabriel-RS, graduada em Pedagogia (URCAMP), especialização em Tecnologias da Informação e da Comunicação Aplicadas à Educação (UFSM), especialização em Mídias na Educação (UFSM), Mestra em Educação em Ciências (UFRGS).

${ }^{2}$ Professora Titular da Faculdade de Educação (UFRGS). Graduada em Pedagogia (CESE), especialização em Alfabetização (PUC- RS), especialização em Educação Popular (UNISINOS), Mestrado em Educação (PUC-RS), Doutorado em Educação (UFRGS), pós-doutora em Educação (PUC-RJ).
}

\begin{tabular}{l|l} 
Recebido em: 05/09/2018 & Aceito em: 17/10/2018
\end{tabular}




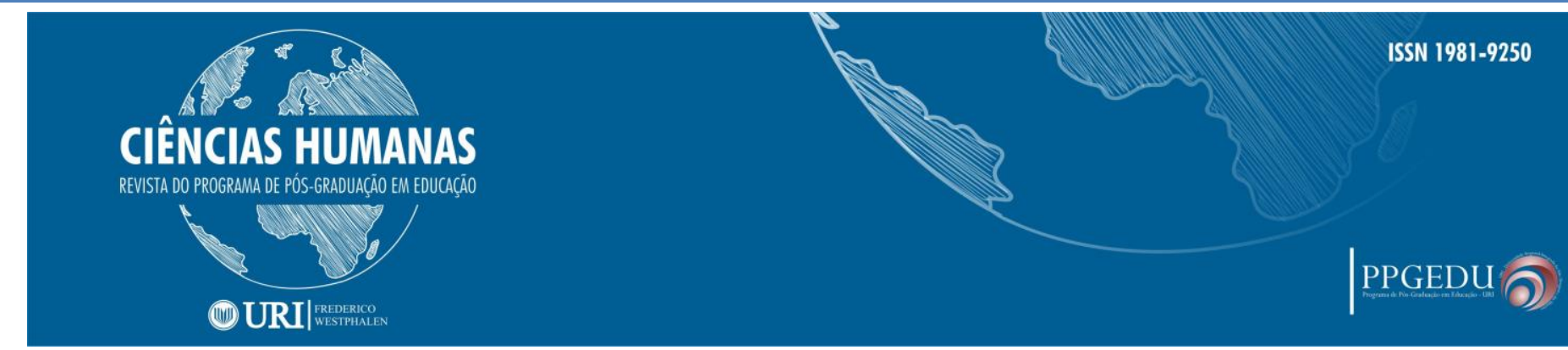

interpretative nature. Data collection was carried out through the activities developed in the workshops, such as field trips, illustrations and practical activities. For the analysis we used the theoretical basis of the authors Auler (2007, 2001), Delizoicov (1992), Angotti (1992 ), Santos and Auler (2011), Bazzo (2001), Freire (1996) and some official documents. The research shows that CTS education by environmental study also considers the social relations and particularities of each territory, according to the presuppositions of integral education, with educational proposals more dialogic, a space to stimulate the reflection of the student about his role of citizen to the places where he lives and circulates. At the end of the work an audiovisual resource was produced with the concepts constructed by the students. The idea was to contribute to the awareness of the problems of the local community, minimizing possible tensions of this nature.

KEYWORDS: CTS. Offices. Garbage. Environment. Citizenship.

\section{RESUMEN}

La educación integral y la educación CTS parten del principio de una formación ciudadana. En este estudio, se buscó con el uso de la fotografía el desarrollo de la capacidad de observación, descripción, y criticidad a partir de la temática social educación ambiental y producir un recurso audiovisual con los conceptos construidos por los alumnos, de esta forma identificar las aproximaciones entre educación integral y, CTS. Así, realizamos talleres pedagógicos bajo la óptica CTS, estructurados en los tres momentos pedagógicos de Delizoicov y Angotti (1992) envolviendo los ejes temáticos: Medio Ambiente, Salud y Sociedad. El enfoque de investigación utilizado fue la investigación participante de carácter cualitativo y naturaleza interpretativa. La recolección de datos fue realizada por medio de las actividades desarrolladas en los talleres, tales como: salidas al campo, ilustraciones y actividades prácticas. Para los análisis utilizamos como base teórica a los autores Auler (2007, 2001), Delizoicov (1992), Angotti (1992) (...), Santos y Auler (2011), Bazzo (2001), Freire (1996) y algunos documentos oficiales. La investigación muestra que la educación CTS por el estudio del medio ambiente también considera las relaciones sociales y las particularidades de cada territorio, los presupuestos de educación integral, con propuestas educativas más dialógicas, un espacio de estímulo a la reflexión del estudiante sobre su papel de ciudadano hacia los lugares por donde vive y circula. Al final del trabajo se produjo un recurso audiovisual con los conceptos construidos por los alumnos. La idea fue contribuir a la concientización de los problemas de la comunidad local, minimizando posibles tensiones de esta naturaleza.

PALABRAS CLAVE: CTS. Talleres. Residuos. Medio ambiente. La ciudadanía.

\section{INTRODUÇÃO}

Este artigo foi estruturado, a partir das experiências vivenciadas em uma escola da rede municipal de ensino da cidade de São Gabriel/RS, no âmbito da pesquisa de mestrado realizada no Programa de Pós-Graduação Educação em Ciências Química da Vida e Saúde da Universidade Federal do Rio Grande do Sul ${ }^{3}$.

O trabalho buscou verificar se, com o uso da fotografia os alunos podem desenvolver capacidade de observação, descrição, e criticidade a partir da educação ambiental e produzir um recurso audiovisual.

\footnotetext{
${ }^{3}$ ALMEIDA, L.H. Entre concepções e práticas de educação integral e educação ambiental: ausências, contradições e possibilidades. Dissertação (Mestrado). Programa de Pós- Graduação em Educação em Ciências, Química da vida e saúde. Universidade Federal do Rio Grande do Sul - UFRGS. 2017. 117 p.
}

\begin{tabular}{l|l} 
Recebido em: 05/09/2018 & Aceito em: 17/10/2018
\end{tabular}




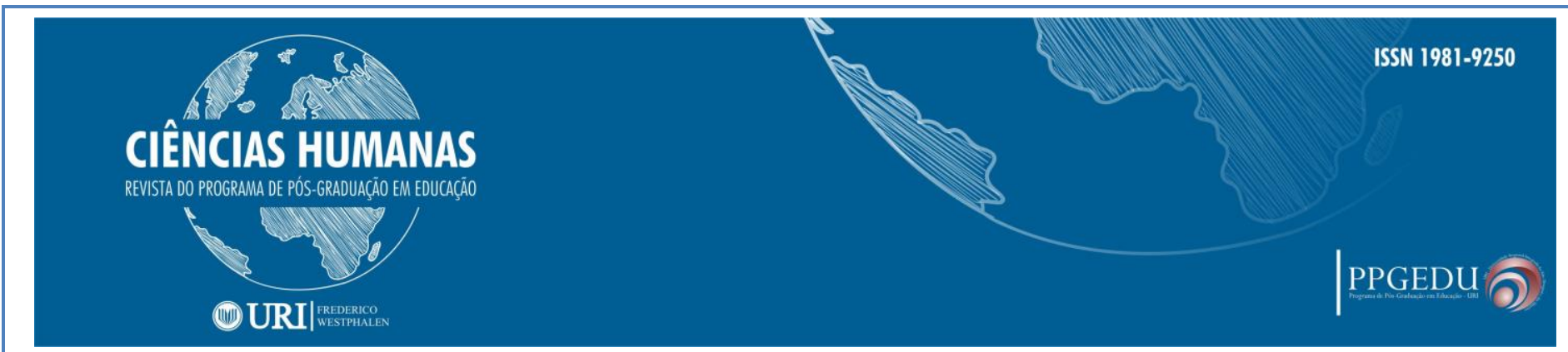

A educação CTS (Ciência, Tecnologia e Sociedade) e a Educação Integral possuem uma compreensão comum acerca do desenvolvimento de todas as potencialidades do indivíduo, considerando os aspectos intelectuais e sociais dos estudantes, e o desenvolvimento de atitudes dirigidas para sustentabilidade socioambiental econômica. "A educação integral envolve formar e informar o tempo todo, rumo a ações transformadoras" (BRASIL, 2013, p.26).

Nessa linha, a formação de sujeitos em uma perspectiva crítica e transformadora, e a ressignificação da escola em espaços educadores sustentáveis é pautada como foco principal destas abordagens.

Partindo destas considerações, é importante investigar quais são as relações das atividades desenvolvidas no Programa Mais Educação com os pressupostos da Educação Integral, identificando aspectos para uma formação de sujeitos autônomos, solidários e responsáveis.

A escolha pela temática Educação CTS e Educação Integral, surgiu do interesse da pesquisadora pelas questões ambientais com enfoque nos resíduos sólidos, que participou da disciplina do mestrado "Reconfigurações possíveis na escola de educação Básica" a qual possibilitou um aprofundamento sobre o tema da educação integral.

A partir disso, observou-se relação entre essas temáticas, o que a levou investigar sobre a compreensão dos sujeitos escolares sobre o Programa Mais Educação (PME) e Educação Integral.

Logo a pesquisa partiu para uma intervenção no âmbito das oficinas do PME, em que foram realizadas sete oficinas com uma abordagem CTS, distribuídas pelas seguintes temáticas: Lixo, Meio Ambiente Saúde e Sociedade.

Neste trabalho apresentamos os resultados das oficinas realizadas com as temáticas Meio ambiente, saúde e sociedade com os subtemas: poluição e as enchentes, lixo e doenças, coleta seletiva, tempo de decomposição dos resíduos, reciclagem bem como a construção de um vídeo ao final das atividades.

\section{EDUCAÇÃO INTEGRAL E CTS (CIÊNCIA, TECNOLOGIA E SOCIEDADE)}

O meio ambiente nas suas mais variadas especificidades vem sofrendo inúmeras crises ambientais, e não é possível classificar os prejuízos em naturais ou sociais, pois eles estão completamente interligados, são estruturados pela vida sociocultural humana. Contudo, a responsabilidade humana parece ser cada vez menos praticada e discutida no mundo contemporâneo.

A sociedade atual está cada dia mais consumista e as tecnologias ocupando lugar maior e de destaque, porém algumas altamente impactantes sem o gerenciamento correto e instrução necessária para seu uso. Esse contexto fortalece a importância de 


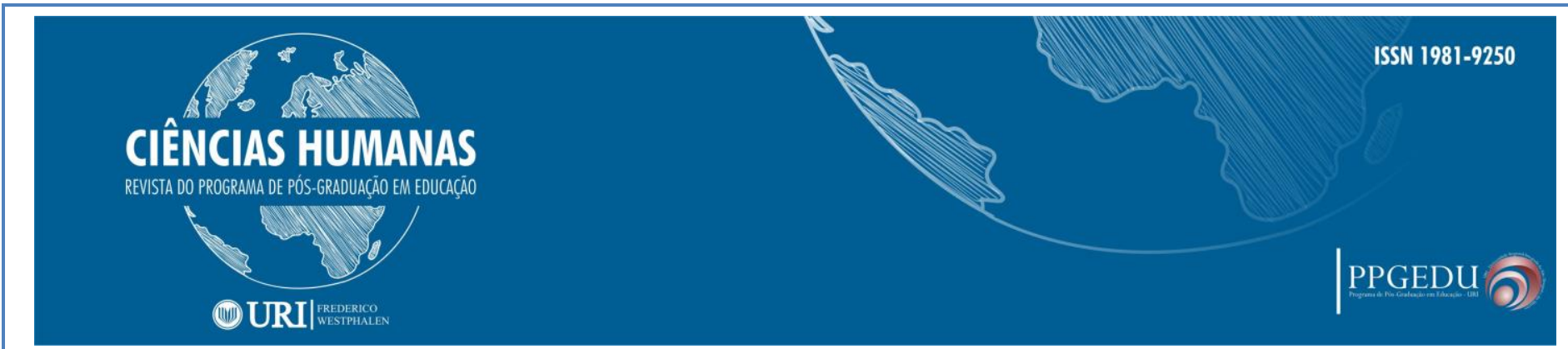

uma educação crítico-transformadora, de uma educação para além dos muros da escola, promovendo atores sociais comprometidos com uma prática político-pedagógica emancipatória.

Com esta proposta surge o Programa Mais Educação como indutor para a consolidação da educação integral no Brasil. O Programa pretende contribuir para diminuição das desigualdades educacionais e busca lutar contra a vulnerabilidade social, na perspectiva de melhorar a qualidade da educação e valorizar a diversidade cultural brasileira.

O Programa Mais Educação foi regulamentado pelo Decreto 7083/10, instituído pela Portaria Normativa Interministerial $n^{\circ} 17 / 2007$, com o objetivo de "[...] fomentar a Educação Integral de crianças, adolescentes e jovens por meio de atividades socioeducativas, no contraturno escolar, articuladas ao projeto de ensino desenvolvido pela escola" (BRASIL, 2013, p. 25).

Assim, oportunizar via escolarização uma formação mais humana as classes populares, ampliando a jornada escolar até o limite mínimo de sete horas.

De acordo com o Manual Operacional de Educação Integral (BRASIL, 2013e),

\begin{abstract}
Essa estratégia promove a ampliação de tempos, espaços, oportunidades educativas e o compartilhamento da tarefa de educar entre os profissionais da educação e de outras áreas, as famílias e diferentes atores sociais, sob a coordenação da escola com seus gestores, professores, estudantes e funcionários. Isso porque a Educação Integral, associada ao processo de escolarização, pressupõe a aprendizagem conectada à vida e ao universo de interesses e de possibilidades das crianças, adolescentes e jovens. (BRASIL, 2013, p. 4)
\end{abstract}

Dessa forma, a Educação Integral por se tratar de uma política educacional dirigida a crianças, jovens e adultos, está presente em inúmeros documentos legais como: Fundo de Manutenção e Desenvolvimento da Educação Básica (FUNDEB), Plano de Desenvolvimento da Escola(PDE), Plano Nacional de Educação (PNE), Lei de Diretrizes e Bases(LDB), Estatuto da Criança e do Adolescente (ECA), Constituição Federal de 1988, dentre outros.

Destacamos aqui as orientações contidas na Constituição Federal de 1988, em seu artigo número $6^{\circ}$ "A educação é o primeiro de dez direitos sociais" e no artigo 205 "a educação é o direito capaz de conduzir ao pleno desenvolvimento da pessoa, fundamento da cidadania e da preparação para o trabalho". Observa-se que a Constituição se refere a uma educação capaz de desenvolver o estudante integralmente, uma educação de qualidade que busca viabilizar todos os direitos destes estudantes (BRASIL, 2013a).

A Lei de Diretrizes e Bases de 1996 (BRASIL, 1996), no art. 34, parágrafo $2^{\circ}$ orienta: "O ensino fundamental será ministrado progressivamente em tempo integral, a critério dos sistemas de ensino". E no artigo 87, parágrafo $5^{\circ}$ : "Serão conjugados todos 


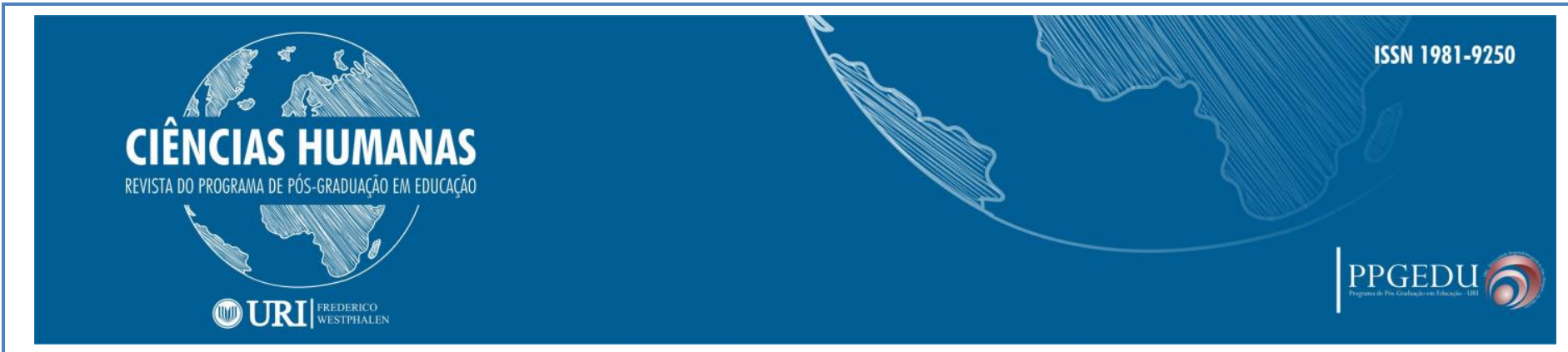

os esforços objetivando a progressão das redes escolares públicas urbanas de ensino fundamental para o regime de escolas de tempo integral" (GIOLO, 2012).

É importante considerar também o Plano Nacional de Educação (PNE), aprovado em 2001, pela Lei 10. 172 (BRASIL, 2001), que também apoia e valoriza a educação integral como uma oportunidade de fomentar a educação integral dos sujeitos. Aborda várias vezes o tema e reivindica essa modalidade para o ensino fundamental e educação infantil. Tendo como meta a ampliação da jornada escolar para sete horas (GIOLO, 2012).

Moll (2014, p. 373) em seu estudo sobre a meta 6 do PNE e a educação integral destaca algumas diretrizes e faz considerações importantes

\begin{abstract}
Explicita-se entre outras a (III) superação das desigualdades educacionais; a (IV) melhoria da qualidade de educação; a (VII) promoção humanística, cientifica, cultural e tecnológica do País; e a (X) promoção dos princípios do respeito aos direitos humanos, à diversidade e à sustentabilidade socioambiental. Tais diretrizes, consideradas profundas desigualdades sociais e educacionais brasileiras, dificilmente poderão ser consideradas e tomadas como referência em uma escola de tempo parcial e fragmentado, descontextualizada social e culturalmente, e, sobretudo, com ênfase em aspectos cognitivos, focados em um modus operandi de exercícios repetitivos, cópias e silenciamentos culturais. (MOLL, 2014, p. 373, grifo da autora).
\end{abstract}

As metas do PNE comprometem-se com uma mudança estrutural no sistema educacional do Brasil, com um compromisso com estudantes das classes populares garantindo uma escola de qualidade. A autora salienta a necessidade de "despatologizar a pobreza e desnaturalizar o fracasso escolar"

\begin{abstract}
Se não mudarmos a perspectiva e o olhar em relação às classes populares, seus filhos poderão ter mais acesso, mas a qualidade e o resultado desse processo não pavimentarão o caminho para uma sociedade efetivamente justa. Serão funcionalmente incluídos, mas não estruturalmente incluídos. (MOLL, 2014, p. 379)
\end{abstract}

O Programa Mais Educação em seu Manual Operacional (2013b) orienta que as atividades de acordo com seu macrocampo ${ }^{4}$, devem partir do contexto social dos sujeitos buscando por um trabalho interdisciplinar, sinaliza que é preciso "fomentar

\footnotetext{
${ }^{4}$ As atividades do Programa Mais Educação são organizadas em macrocampos, que podem ser entendidos como temáticas ou campos do conhecimento. São eles: Acompanhamento Pedagógico; Desenvolvimento Sustentável e Economia Criativa/ Educação Econômica; Esporte e Lazer; Cultura, Artes e Educação Patrimonial; Comunicação, uso de Mídias e Cultura Digital e Tecnológica; Educação em Direitos Humanos; Promoção da Saúde. De acordo com o Manual Operacional de Educação Integral (2014), as atividades são distribuídas em: Linguagens, Matemática, Ciências da Natureza e Ciências Humanas que constituem o currículo da base nacional comum. Como esta pesquisa foi realizada em 2015, consideramos os macrocampos vigentes no ano de 2015, visto que em 2016 surgiu uma nova Portaria com o Programa Novo Mais Educação, que sua proposta e macrocampos são divergentes.
}

\begin{tabular}{l|l|l|l}
\hline Rev. Ciências Humanas & Frederico Westphalen, RS & Pg. $118-142$ & mai./ago. 2018
\end{tabular}

\begin{tabular}{l|l} 
Recebido em: 05/09/2018 & Aceito em: 17/10/2018
\end{tabular}




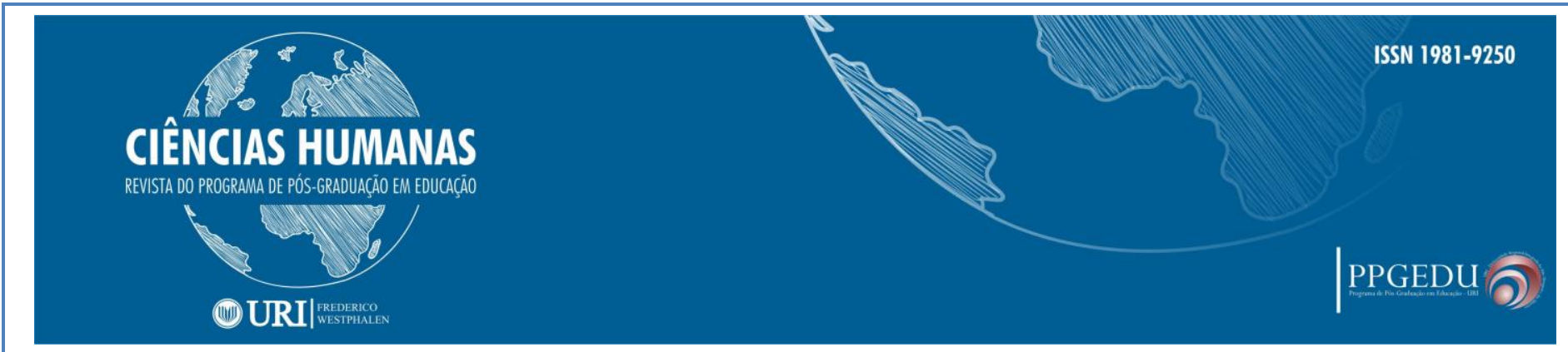

práticas educativas que promovam aos estudantes a compreensão do mundo em que vivem, de si mesmo, do outro, do meio ambiente, da vida em sociedade, das artes, das diversas culturas, das tecnologias e de outras temáticas" (BRASIL, 2013b, p. 10).

Nesse sentido, a educação integral e a educação CTS se alinham em suas propostas, promovendo uma educação mais dialógica e transformadora. Com uma perspectiva de ressignificar a educação, articulando o ambiente e as mudanças socioambientais, reelaborando práticas diárias.

Trajber (2012, p. 176) considera uma educação de qualidade, integral e transformadora aquela que "seja capaz de estimular os processos investigativos, a pesquisa, a interpretação da paisagem, a compreensão da realidade local e global e a construção de identidades próprias, individuais e coletivas, orientadas pedagogicamente".

A educação CTS surgiu nos anos de 1960 e 1970, quando o desenvolvimento científico e tecnológico teve uma grande projeção. Trouxe em suas bases uma reavaliação crítica do papel da ciência e da tecnologia na sociedade.

De acordo com Auler (2007) os estudos CTS tem como objetivo:

\begin{abstract}
promover o interesse dos estudantes em relacionar a ciência com aspectos tecnológicos e sociais e éticas relacionadas ao uso da ciência-tecnologia (CT), adquirir uma compreensão da natureza da ciência e do trabalho científico, formar cidadãos científica e tecnologicamente alfabetizados, capazes de tomar decisões informadas e desenvolver o pensamento crítico e a independência intelectual.(AULER, 2007, p. 1)
\end{abstract}

As propostas curriculares organizadas sobre esta ótica trazem ao contexto escolar questões sociocientíficas, almejando construir princípios para cidadania, justiça social e transformação da sociedade.

Com essa abordagem, diversas habilidades são desenvolvidas e valorizadas, visto que, a educação CTS se destina a formação cidadã, desenvolvendo as capacidades de se expressar, ouvir, argumentar e agir de forma articulada, cooperativa na resolução de problemas que afetam a sociedade. (SANTOS; MORTIMER, 2009).

Torna-se urgente para a consolidação de uma formação mais humana e integral,uma metodologia embasada em diálogo e problematização de situações do contexto dos estudantes, onde educadores e educandos possam ser sujeitos e protagonistas da aprendizagem.

Sobre isso, Henz (2012) afirma que:

trata-se de ir construindo processos em que todos, dialógica e reflexivamente, vão se assumindo como sujeitos do quefazer pedagógico e social, descobrindo-se capazes de (re) humanizar a escola e a sociedade, capazes de (re) humanizar a si mesmos na incertezado seu corpo consciente. (HENZ, 2012, p. 82, grifo do autor). 


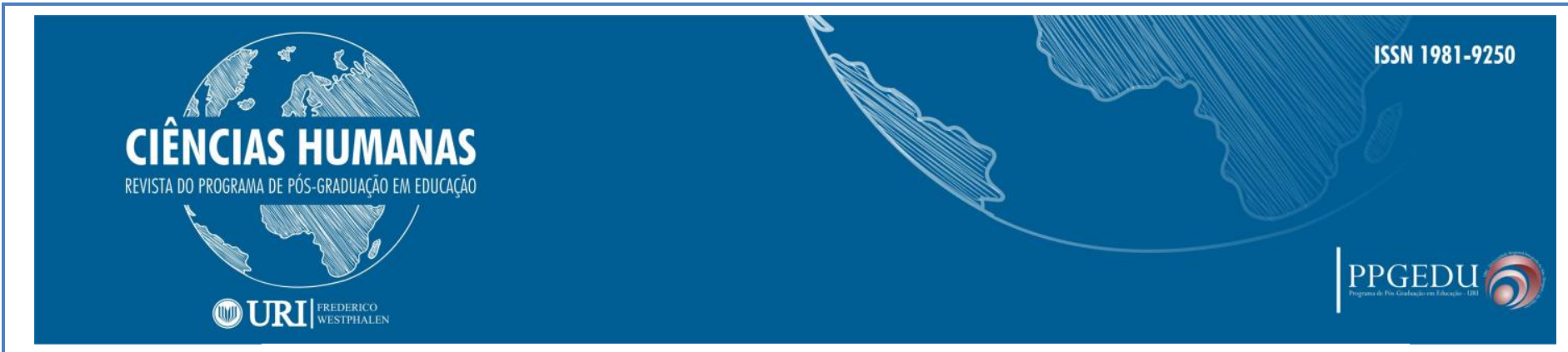

As experiências e vivências na construção do saber e no descobrimento enquanto ser humano crítico e reflexivo, é que os estudantes levam da escola para sua vida, sua capacidade de transformar suas realidades, construindo caminhos mais esperançosos em âmbitos variados desde o humano, intelectual, físico, social ao afetivo.

\section{PROCESSO E LÓCUS DA PESQUISA}

A abordagem de pesquisa utilizada neste estudo foi a pesquisa participante de caráter qualitativo e natureza interpretativa. Neste artigo buscou-se também observar as proximidades da educação CTS com a proposta de Educação Integral. Para tanto, a pesquisa foi desenvolvida a partir de uma intervenção realizada junto aos alunos participantes do Programa Mais Educação de uma escola da rede municipal de ensino de São Gabriel/RS, no segundo semestre de 2015.

Para as análises deste estudo utilizamos como embasamento teórico os autores Auler (2007, 2001), Delizoicov e Angotti (1992), Santos e Auler (2011), Bazzo(2001), Freire (1996) e alguns documentos oficiais.

A escola onde foi desenvolvida a pesquisa se localiza em uma área de vulnerabilidade social, o bairro fica distante do centro da cidade, e conta com serviço de uma empresa de ônibus.

A Escola foi fundada no ano de 1978, pelo Decreto de Criação n014, de 26/06/78. Atualmente atende em torno de 478 alunos distribuídos em dois turnos, dentro deste universo 215 alunos são beneficiários do Programa Bolsa Família (PBF), conforme informação contida no relatório de frequência dos alunos cadastrados no PBF de 2015.

As propostas das atividades foram estruturadas a partir de oficinas pedagógicas organizadas nos Três Momentos Pedagógicos de (DELIZOICOV; ANGOTTI, 1992). A seguir apresentamos brevemente os eixos Meio ambiente, Saúde e Sociedade.

Meio ambiente: A partir das reflexões sobre os conceitos de poluição e algumas problematizações sobre as enchentes na cidade de São Gabriel/RS, os alunos fizeram um passeio aos arredores da escola, observando e fotografando os aspectos positivos e negativos sobre o meio ambiente, ponderando o que precisa melhorar no meio ambiente ao redor da escola e o que poderia ser feito para isto se concretizar.

Brandão e Streck (2006) comentam sobre os princípios fundadores para as ideias e propostas de pesquisa participante, buscando tornar mais atuais as palavras dos autores

O ponto de origem da pesquisa participante deve estar situado em uma perspectiva de realidade social, tomada como uma totalidade em sua estrutura e em sua dinâmica. Deve-se partir da realidade concreta da vida cotidiana dos próprios participantes individuais e coletivos do processo, em suas diferentes dimensões e interações. (BRANDÃO; STRECK, 2006, p. 41) 


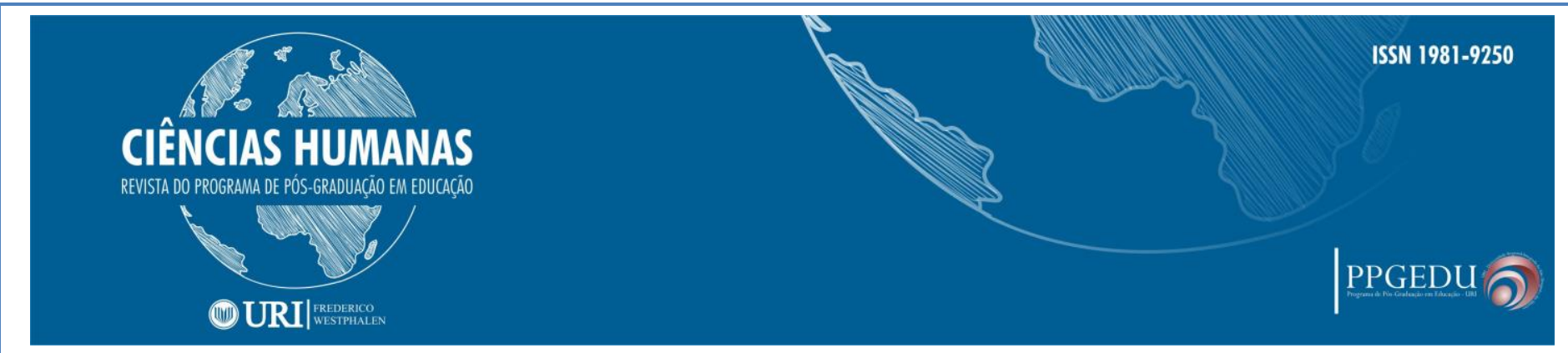

Saúde: Nessa etapa, por meio de discussões sobre a os agentes transmissores de doenças presentes nos resíduos sólidos quando descartados em locais inapropriados, os alunos desenvolveram um experimento que mostrava a importância de lavar bem as mãos e aplicaram com alguns estudantes de outras turmas da escola.

Brandão e Streck (2006, p. 42) destacam que "o conhecimento científico e o popular articulam-se criticamente em um terceiro conhecimento novo e transformador. "A pesquisa participante é um processo dinâmico de ação social popular. Busca relação da teoria com a prática, refletindo criticamente para assim construir seu conhecimento.

Sociedade: Nesta etapa, os alunos fizeram uma visita aos pontos de coleta de lixo de São Gabriel/RS, um antigo aterro sanitário e uma cooperativa de reciclagem. Nesta etapa também foi desenvolvido um vídeo com os conceitos construídos pelos estudantes durante as oficinas que foi utilizado como recurso informativo para a população, em diversos espaços da comunidade como: sala de espera da prefeitura e espaços de propagandas de mídias na praça central da cidade.

Para Brandão e Streck (2006, p. 31),“uma pesquisa é participante não porque atores sociais populares participam como coadjuvantes dela, mas sim porque ela se projeta, porque ela realiza desdobres por meio da participação ativa e crescente desses atores".

Três Momentos Pedagógicos: As oficinas pedagógicas desenvolvidas neste trabalho foram elaboradas segundo os Três Momentos Pedagógicos (3MP), apresentados por Delizoicov e Angotti (1992), estruturada em: Problematização Inicial (PI), Organização do Conhecimento (OC) e Aplicação do Conhecimento (AC).

Na Problematização Inicial, o tema é apresentado com as situações cotidianas dos estudantes, de forma que possa aguçar a sua curiosidade ele sinta a necessidade de obter outros conhecimentos, contemplando situações problema que precisam ser enfrentadas.

$\mathrm{Na}$ segunda etapa (OC, Organização do Conhecimento), o professor irá selecionar conceitos físicos e científicos das situações problematizadas para serem estudados, discutidos e exercitados por meio de diferentes atividades. Neste momento que o estudante irá encontrar soluções para os problemas da primeira etapa (PI), de forma que estes ganharão significado, levando o aluno a apropriação destes conhecimentos.

Aplicação do conhecimento (AC), neste momento acontece a sistematização do conhecimento que foi abordado nas etapas iniciais com acontecimentos relacionados ao objeto principal de estudo e as suas influências externas. 


\section{OS ACHADOS DA PESQUISA}

A coleta de dados ocorreu durante odesenvolvimento das atividades. Para analisar os resultados, foi feita uma leitura criteriosa das anotações no diário de campo, da escuta das gravações, bem como o estudo e interpretação das atividades desenvolvidas pelos estudantes.

As atividades foram separadas por eixos temáticos para atender os objetivos aqui propostos. Dessa forma apresentaremos os resultados de cada eixo temático a seguir:

Nas oficinas com o tema Meio Ambiente, na problematização inicial, os alunos assistiram a vídeos sobre enchentes ocorridas nos últimos dois anos no município de São Gabriel/RS, visto que a enchente ocorrida no ano de 2015 foi considerada a maior cheia dos últimos quinze anos no município.

A Problematização Inicial aconteceu na forma de roda de conversa, algumas questões foram abordadas, tais como: O que você acha que provoca a enchente? O lixo pode ser considerado um dos responsáveis pela enchente?Qual foi o papel dos resíduos sólidos nessa situação? Qual o nível de conscientização ambiental da população? Essa catástrofe poderia ocorrer na sua região ou no seu bairro? Por quê? O que você entende por conscientização ambiental?

Durante este momento vários alunos comentaram que suas casas foram atingidas pela enchente. Dentre os alunos presentes, apenas $40 \%$ (04) não vivenciaram situações de enchentes em suas residências, o restante dos alunos experienciaram situações de alagamentos. Diante desses relatos outras questões surgiram ao natural. Os alunos em sua totalidade associaram consciência ambiental à prática de atitudes de cuidado com o meio ambiente, como citado durante as rodinhas de conversa: "comprar menos coisas", "menos lixo", "menos fumaça".

Desde a problematização inicial e durante toda a oficina, foram utilizadas estratégias metodológicas em que os alunos eram incentivados a refletir sobre suas atitudes, sobre os fenômenos ligados ao seu contexto e a tomada de decisões, possibilitando o desenvolvimento de uma abordagem CTS entrelaçada nos pressupostos da educação integral.

Silva, Oliveira e Queiroz (2011, p. 325), evidenciam que para atingir os objetivos da educação CTS, além de trabalhar conteúdos de natureza sociocientífica, a abordagem deve "favorecer a participação ativa dos estudantes e o desenvolvimento de tomada de decisão."

A abordagem CTS, segundo Santos (2011, p. 23) tem como objetivo o "desenvolvimento da capacidade de tomada de decisão na sociedade científica, tecnológica e o desenvolvimento de valores". 


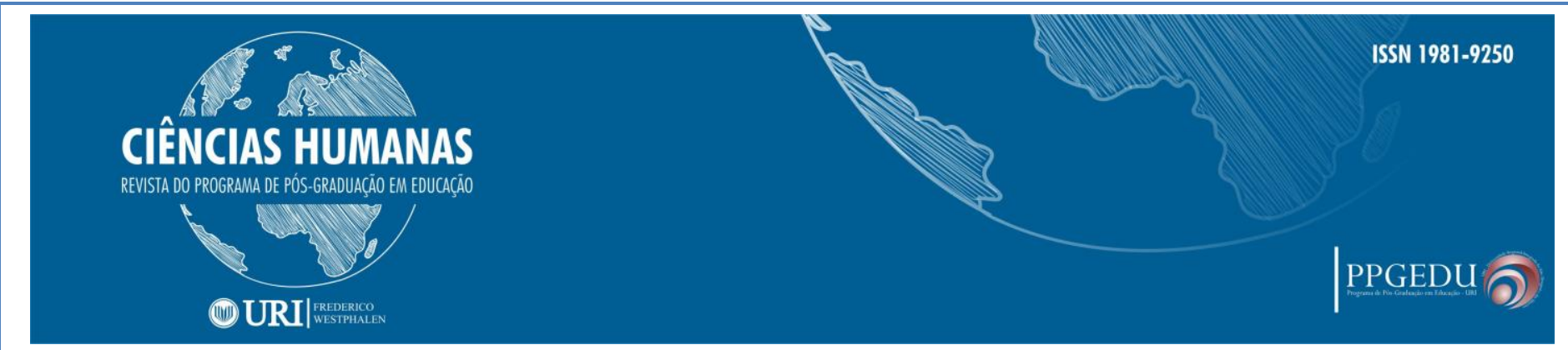

Portanto, é preciso trabalhar na perspectiva de uma formação integral dos sujeitos, reconhecendo-os como sujeitos participantes e agentes de transformação e produção do conhecimento.

De acordo com o Manual Operacional do Mais Educação (BRASIL, 2013b), as atividades devem privilegiar, "os processos capazes de gerar sujeitos inventivos, autônomos, participativos, cooperativos e preparados para diversificadas inserções sociais, políticas, culturais, laborais e, ao mesmo tempo, capazes de intervir e problematizar as formas de produção na sociedade atual" (BRASIL, 2013b, p. 10).

O trabalho pedagógico desenvolvido nas atividades oferecidas no Programa Mais Educação, contribuem para essas discussões na escola, por proporcionar uma jornada ampliada, um tempo a mais na escola. A proposta de educação integral propõe uma nova organização de tempos e espaços, considerando o estudante como um ser social e histórico.

Quando questionados sobre a conscientização da população, os estudantes relataram aspectos negativos observados nas atitudes de seus vizinhos, familiares e amigos. Comentaram, a falta de lixeiras no bairro onde residem, próximo a escola. Observe abaixo as respostas dos alunos sobre a pergunta como seria uma cidade sem poluição?

TABELA 1 - Respostas dos alunos a pergunta "Como seria uma cidade sem poluição?" Como seria uma cidade sem poluição?

Aluno A "Uma cidade limpa."

\begin{tabular}{ll}
\hline Aluno B & "Melhor para respirar" \\
\hline Aluno C & "Uma cidade limpa e as pessoas com mais consciência das coisas." \\
\hline
\end{tabular}

Aluno D "Que as pessoas sempre colocassem lixo na lixeira."

Fonte: Pesquisa de campo na rede municipal de ensino de São Gabriel - RS.

Observou-se nas respostas que os estudantes não possuíam bem definido a ideia de um modelo de organização sustentável de uma cidade, direcionando a conversa para organização do espaço urbano. Alguns relataram que suas casas tinham alagado mais de uma vez, e deram ênfase sobre o número reduzido de lixeiras no bairro.

Mencionaram o nome do prefeito da cidade e a possibilidade de solicitar mais lixeiras. Observando o papel das autoridades para resolução das questões sobre as lixeiras nos bairros e a prevenção das enchentes e aos fatores ligados a este problema social.

No momento da discussão do tema a poluição e as enchentes, os estudantes observaram várias causas resultantes da atuação humana, proporcionando o debate sobre produção de lixo, sociedade de consumo (assunto já tratado em outra oficina), 


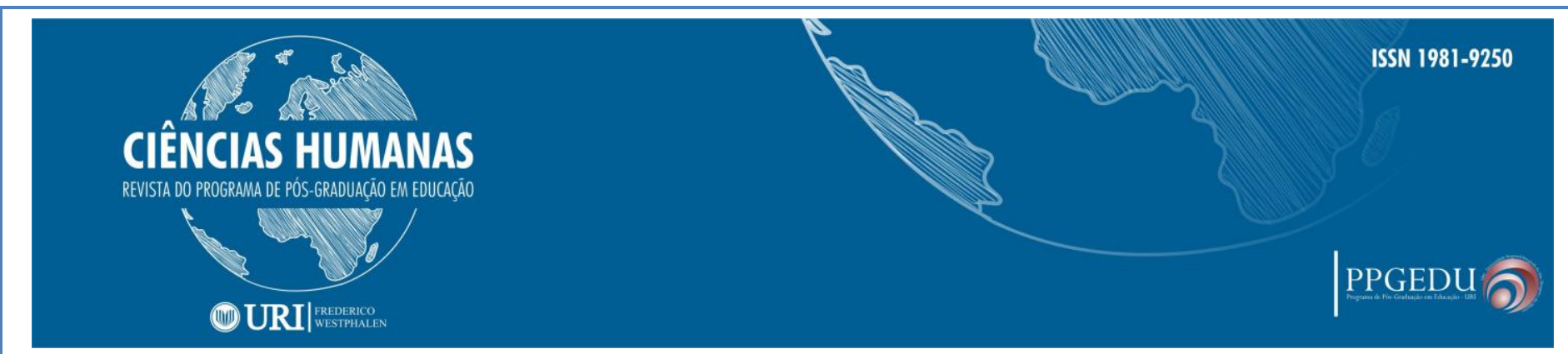

doenças transmitidas pela água contaminada (tema que foi abordado na oficina posterior a esta) englobando na discussão aspectos ambientais, políticos, tecnológicos, valores e atitudes dentre outros.

Assim, os assuntos que surgiram foram discutidos, mas alguns não houve tempo para aprofundar, devido ao cronograma das atividades. Observa-se que estes são temas oportunos no contexto de educação nacional, pois estão presentes nos documentos oficiais e segundo Auler (2007), partem de situações-problema relativas ao contexto real de relevância social, isto é, trazem o "mundo da vida" para o "mundo da escola."

$\mathrm{O}$ autor destaca ainda que em uma perspectiva freireana temas/problemas de cunho social, próximo a realidades dos estudantes estimulam a ampliar e alcançar umavisão global da sociedade, fomentando a aprendizagem e a construção de uma cultura de participação.

Assim, foi feito um passeio no quarteirão ao redor da escola, durante este passeio os alunos tinham como tarefa fotografar ambientes considerando aspectos positivos e negativos, os alunos em trio elegeram duas fotos por grupo, e logo após tinham que apresentar a que mais marcou para os demais colegas.

O primeiro trio elegeu uma foto de um pátio que estava limpo como aspecto positivo e como aspecto negativo uma árvore que havia sido cortada e seus pedaços estavam em uma casa abandonada.

O segundo trio elegeu como aspecto positivo o fato de terem encontrado no bairro um (PV) ponto de entrega ${ }^{5}$ voluntária de lixo orgânico (imagem 1), consideraram positivo pelo fato de ser um bairro afastado do centro da cidade, porém criticaram o fato de que os moradores estavam colocando outros tipos de resíduos no PV. Como aspecto negativo o trio escolheu uma foto de um terreno vazio que havia uma placa de proibido colocar lixo e juntamente a leiregulamentadora, e mesmo assim os moradores continuavam a colocar lixo naquele local (imagem 2).

\footnotetext{
5 "Os PEVs ou PVs (postos de entrega voluntária) ou LEVs (locais de entrega voluntária) são uma alternativa para a realização do recolhimento de materiais urbanos recicláveis. São criados pela prefeitura e estão instalados em diversas cidades, com o objetivo único de diminuir a quantidade de lixo descartado em locais públicos, terrenos baldios e córregos. Evitando assim a proliferação de doenças, enchentes e de animais que são atraídos pelo acúmulo de lixo.Os postos de entrega voluntária são preparados para receber os materiais de coleta seletiva já conhecidos como: plástico, papel, vidro e metal" (ALBUQUERQUE, 2017, p. 01).
} 

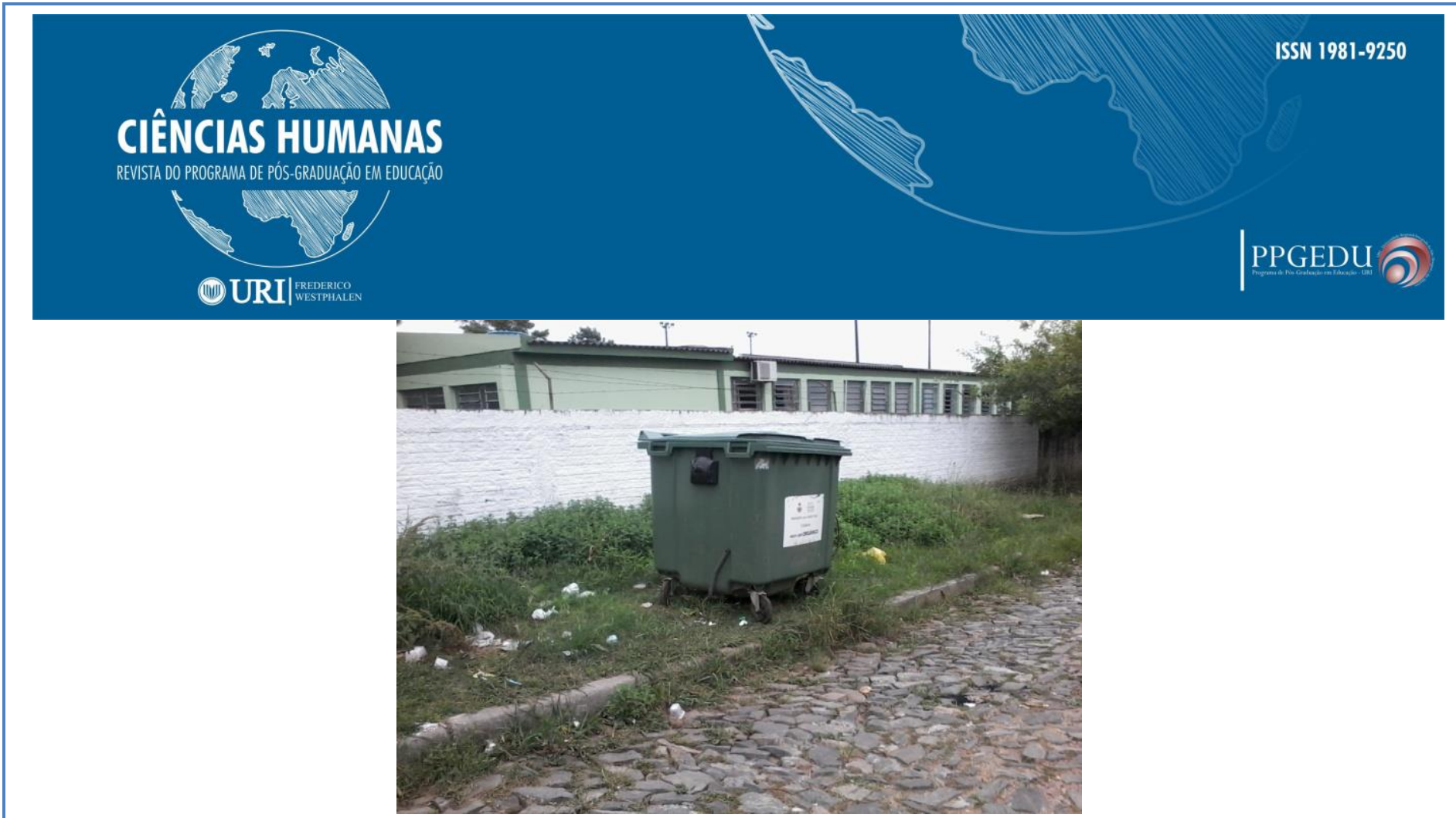

FIGURA 1 - Foto tirada pelos alunos

Fonte: Pesquisa de Campo na rede municipal de ensino de São Gabriel-RS

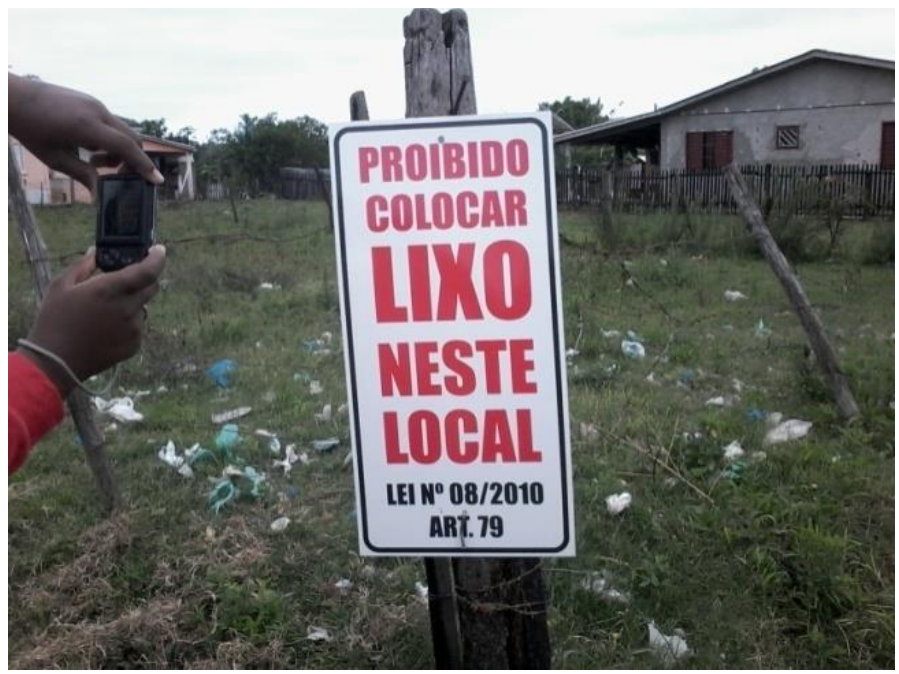

FIGURA 2 - Foto tirada pelos alunos

Pesquisa de Campo na rede municipal de ensino de São Gabriel-RS

O terceiro grupo escolheu a foto de um senhor varrendo a rua em frente à sua casa, pois consideraram que mesmo sua casa estando limpa ele quis contribuir para a limpeza da rua, juntando resíduos que não eram seus. Logo, como aspecto negativo o trio elencou a foto de um bueiro cheio de lixo.

Considerando que todos os alunos residiam próximos a escola a tarefa, de fotografar, fez com que eles percebessem problemas no seu território e identificassem possíveis alternativas para minimizá-los. No processo de construção de conhecimento, é fundamental propiciar momentos em que os alunos percebam e compreendam que a Ciência está presente no seu cotidiano, e que o seu estilo de vida e a forma como utilizam tecnologias geram impactos sociais, ambientais e econômicos. 


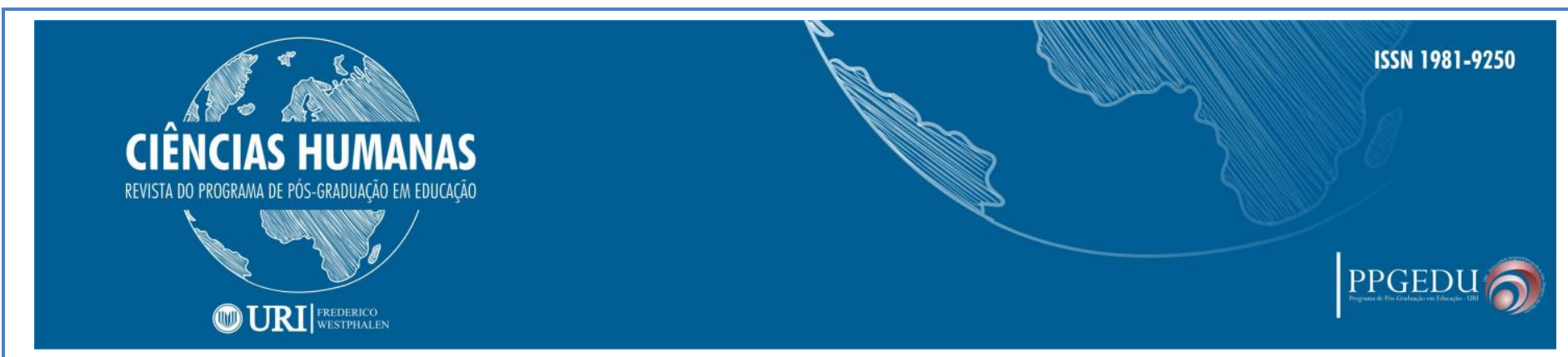

Porém, isto ainda é um desafio, pois os conteúdos escolares ainda estão subdivididos e algumas vezes distanciados da realidade. Aikenhead (2005, 2006apud SANTOS, 2011, p. 28) afirma que "resultados de pesquisas que demonstram como propostas de ensino CTS têm contribuído para a maioria dos estudantes da educação básica que apresentam dificuldades com o ensino tradicional de Ciências."

É importante destacar o caráter interdisciplinar de CTS, porém ainda enfrentamos este desafio, nos próprios cursos de licenciatura em que as disciplinas são fragmentadas, e isto reflete nas escolas com programas de ensino mais fechados (BERNARDO, 2008).

Contudo, é preciso investir em uma formação cidadã, uma formação mais crítica e bem informada sobre os problemas locais e globais. Em concordância com estas ideias Martins e Paixão (2011 ressaltam que

\begin{abstract}
O ensino das Ciências, para todos os níveis de escolaridade, deve preocuparse com outras dimensões do saber, para além dos conteúdos disciplinares específicos. Conhecer os contextos nos quais os problemas se colocam, as variáveis que os afetam e os valores que subjazem à procura de soluções são de enorme importância. A orientação CTS tem esta perspectiva de educação em mente. (MARTINS; PAIXÃO, 2011, p. 140)
\end{abstract}

Em consonância com estas questões, o Programa Mais Educação, propõe uma ampliação dos tempos e espaços/ territórios e das oportunidades educativas, bem como Moll (2013), afirma sobre os aspectos a serem considerados na construção do ProjetoPolítico-Pedagógico na perspectiva da educação integral.

Consideram-se as experiências que já são vividas na escola (muitas vezes em termos de atividades complementares), ampliando-se espaços para além do ambiente de sala de aula e aproximando-se saberes e práticas culturais comunitárias e populares com conteúdos denominados acadêmicos. (MOLL, 2013, p. 76)

Nas oficinas com o tema Saúde, os alunos assistiram ao filme "Tá limpo", a partir deste filme podemos citar algumas problematizações: Qual a forma de descarte do lixo no filme? Existem bichinhos que moram no lixo? Que tipos de bichinhos?Esses bichinhos podem chegar até a nossa boca? Como isso acontece? Os bichinhos são bons ou maus? O que eles podem fazer aos seres humanos? A sujeira pode causar doenças? Quais? O que devemos fazer para nos prevenirmos dessas doenças? "Lixo não é lixo" explique esta afirmativa.

$\mathrm{Na}$ organização do conhecimento, foi explicada a importância da higiene pessoal, de lavar as mãos e alimentos antes de comê-los, principalmente para a prevenção de doenças. Foram projetados no multimídia alguns animais (possíveis

${ }^{6}$ Filme "Tá limpo", disponível em: https://youtu.be/mVnX2ZGlo3k

\begin{tabular}{l|c|c|c} 
Rev. Ciências Humanas & Frederico Westphalen, RS & Pg. 118 - 142 & mai./ago. 2018
\end{tabular}

\begin{tabular}{l|l} 
Recebido em: 05/09/2018 & Aceito em: 17/10/2018
\end{tabular}




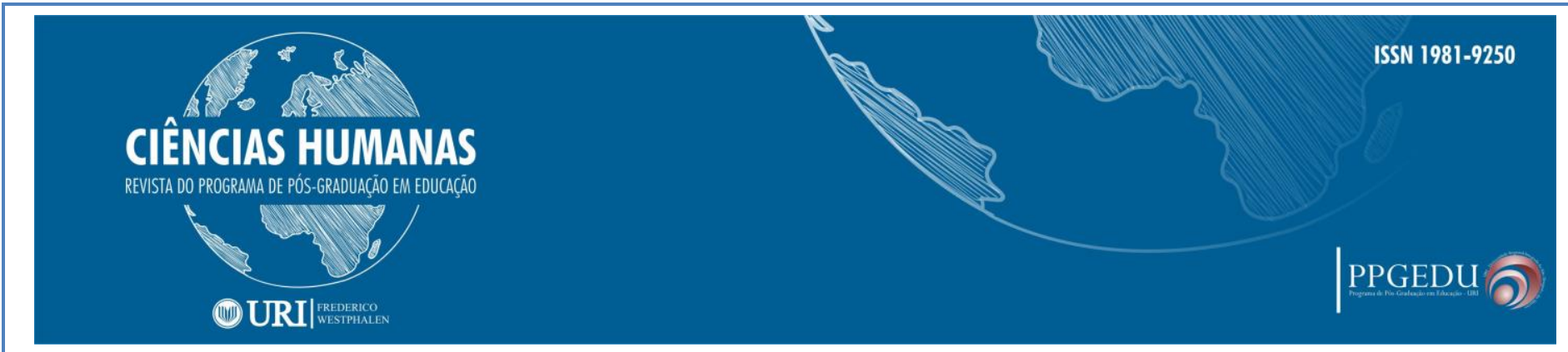

vetores), formas de transmissão de doenças, e as enfermidades que podem surgir por este contagio.

Os alunos fizeram um experimento sobre a transmissão de doenças causadas por bactérias presentes nas mãos. Durante a atividade, usaram caneta marca-texto, extraíram sua tinta e misturaram ao álcool, sujaram as mãos com o fluído e esperaram elas se secarem. Os educandos notaram que suas mãos, quando se secaram, pareciam limpas, mas, ao observá-las sob a luz negra, viram que estavam fluorescentes. O objetivo era fazer com que os alunos pudessem perceber que apesar das bactérias não serem vistas a olho nu, elas estão presentes e assim observar quais os locais das mãos precisam de mais atenção na hora de lavá-las, como nas cutículas das unhas, por exemplo, entendendo que esse é um local que pode armazenar bactérias que podem causar doenças.

No terceiro momento aplicação do conhecimento, os alunos convidaram os estudantes do $1^{\circ}$ ao $3^{\circ}$ anos do ensino fundamental para utilizar o experimento $\mathrm{e}$ observar. Explicaram osconceitos estudados e a possibilidade de transmissão de doenças, entregaram panfletos informativos de como lavar as mãos corretamente.

No último bloco temático desta pesquisa, com o tema Sociedade, foi realizada uma visita até a Associação de catadores $^{7}$ Sepé Tiarajú. Esta associação foi desenvolvida pela ONG Planeta Vivo em parceria com a prefeitura com o Projeto Minuano $^{8}$ (esta associação é responsável pela coleta seletiva de São Gabriel/RS) e também visitamos o antigo aterro sanitário do município.

Cabe destacar que o aterro deixou de ser utilizado no início do ano de 2015 para fins de depósito final dos resíduos, por não estar em conformidade com as normas daFundação Estadual de Proteção Ambiental Henrique Luis Roessler (FEPAM) ${ }^{9}$.

Atualmente o local onde funcionava o aterro é utilizado por uma empresa que faz a coleta de lixo no município, onde os resíduos são levados para este local somente para serem pré-selecionados e o transbordo final é transportado para o aterro sanitário da cidade de Santa Maria/RS.

\footnotetext{
${ }^{7}$ De acordo com o Ministério do Meio Ambiente, catadores, são pessoas que "atuam nas atividades da coleta seletiva, triagem, classificação, processamento e comercialização dos resíduos reutilizáveis e recicláveis". Disponível em: http://www.mma.gov.br/cidades-sustentaveis/residuos-solidos/catadoresde-materiais-reciclaveis

“'O Projeto Minuano, de âmbito estadual, é desenvolvido pela ONG Planeta Vivo, patrocinado pela Petrobras, com o apoio de prefeituras e entidades da sociedade civil. O programa, que já abrange dezenas de municípios gaúchos, colabora na organização dos catadores e no fornecimento de equipamentos necessários a fim de qualificar seu trabalho e de melhorar a qualidade de vida das famílias envolvidas nestas atividades". Disponível em: http://www.planetavivo-rs.org.br/

${ }^{9}$ A Fundação Estadual de Proteção Ambiental Henrique Luis Roessler* - FEPAM,é a instituição responsável pelo licenciamento ambiental** no Rio Grande do Sul. Desde 1999, a FEPAM é vinculada à Secretaria Estadual do Meio Ambiente - SEMA". Disponível em: http://www.fepam.rs. gov.br/institucional/institucional.asp
}

\begin{tabular}{l|c|c|c}
\hline Rev. Ciências Humanas & Frederico Westphalen, RS & Pg. 118 - 142 & mai./ago. 2018 \\
\hline
\end{tabular}

\begin{tabular}{l|l} 
Recebido em: 05/09/2018 & Aceito em: 17/10/2018
\end{tabular}




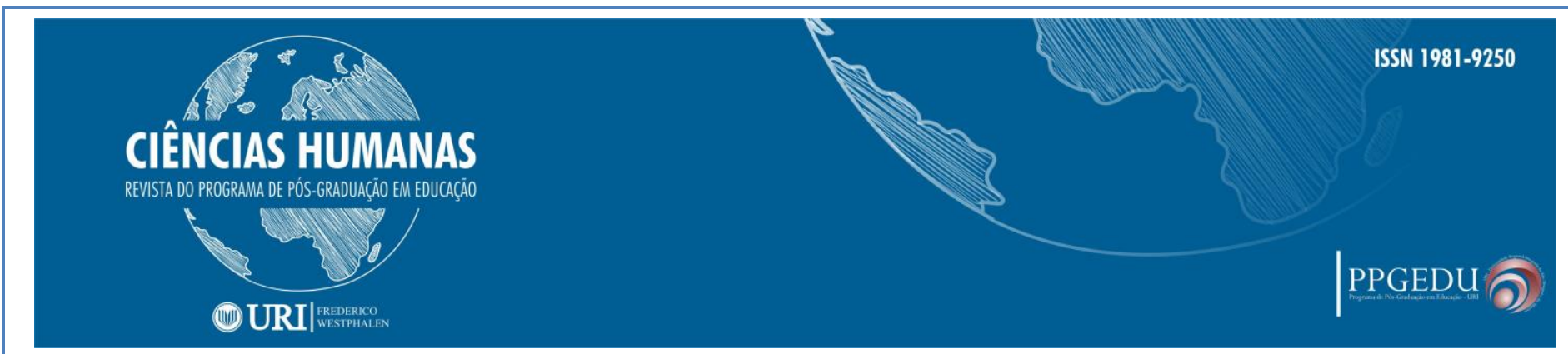

Conhecer as consequências das atitudes que tomamos em relação ao meio ambiente é de extrema importância, sendo que estas devem ser espelho daquilo que já foi aprendido e refletido. Para tanto, é muito válido que se saiba quanto tempo cada tipo de componente, após termos utilizado, passa a ser lixo e perdura na natureza lhe causando danos quando não é destinado aos locais corretos.

Ao retornar para a escola, os alunos participaram de uma roda de conversa da problematização inicial. Nesse momento, alguns dos questionamentos que surgiram foram: O que você sentiu durante o passeio no aterro sanitário?Como é o lugar?Os funcionários usam equipamentos de proteção para trabalhar no aterro sanitário? Se sim, você acha que eles deveriam usar? Os funcionários usam equipamentos de proteção para trabalhar no projeto dos catadores de São Gabriel? Você acha que eles deveriam usar? Por quê?Quais as diferenças que você observou durante o passeio?Para onde vai o lixo que separamos em nossa casa?Para onde vai o lixo que não separamos?

$\mathrm{Na}$ organização do conhecimento, foram discutidas as condições ambientais dos órgãos responsáveis pela coleta de resíduos da cidade. Comparações e análises das diferenças dos locais que recebem resíduos já selecionados dos que não recebem os resíduos selecionados. Os estudantes caracterizaram algumas doenças, suas causas, formas de transmissão e prevenção. Analisaram o tempo de decomposição do lixo. Compreendendo a importância de separar os resíduos e como fazê-la.

No terceiro momento, na aplicação do conhecimento, fizeram uma campanha informativa na escola, na intenção de fortalecer a divulgação sobre a coleta seletiva em nossa cidade, entregaram panfletos e ratificaram a importância de observar os dias e horários que o caminhão da coleta seletiva passa em cada bairro.

Neste momento também chamaram a atenção da comunidade escolar, que fazer a separação do lixo em nossa cidade além de contribuirmos com o meio ambiente, ao facilitarmos o trabalho da associação dos catadores, estamos ajudando as famílias que trabalham neste projeto. Aproximadamente dezoito famílias que eram catadores da rua, foram empregadas nesta associação de catadores.

Observou-se que a conversa dos alunos com os trabalhadores da associação despertou também interesse por parte dos estudantes em ajudar estas famílias, promovendo empatia com os personagens centrais, ou seja, o fato dos estudantes se sensibilizarem com situação influenciará as decisões feitas por eles (HERREID, 1998).

Ainda nesta oficina, foi solicitado aos alunos que desenhassem novamente o destino do lixo de suas casas e as impressões que eles tiveram durante o passeio e respondessem a um questionário com oito perguntas abertas.

Em relação aos desenhos, observamos que enquanto desenhavam eles comentavam vários aspectos que chamaram atenção durante o passeio como, por exemplo: a prensa de materiais plásticos, o processo de triagem dos materiais, os blocos 


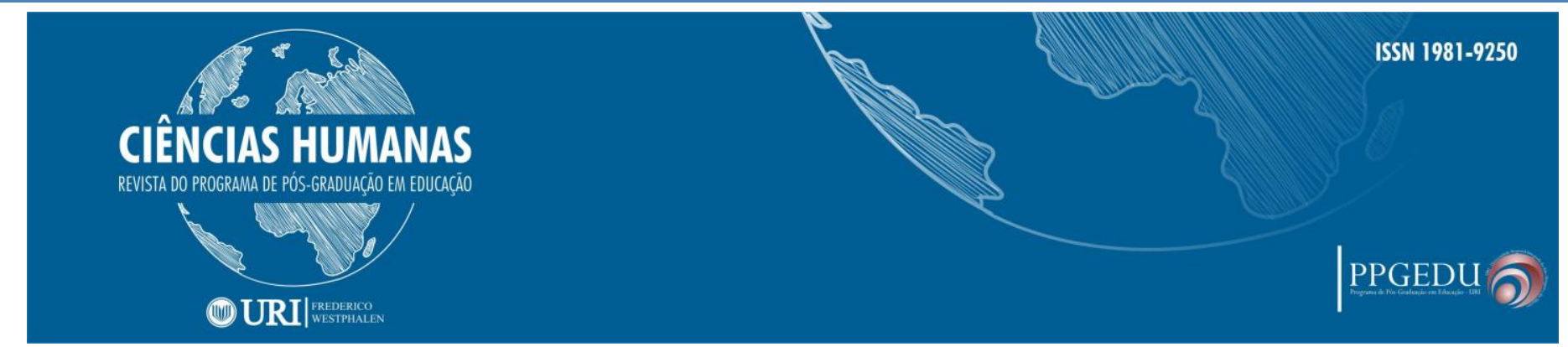

com os materiais já separados, dentre outros, e se preocuparam em ilustrar esses aspectos.
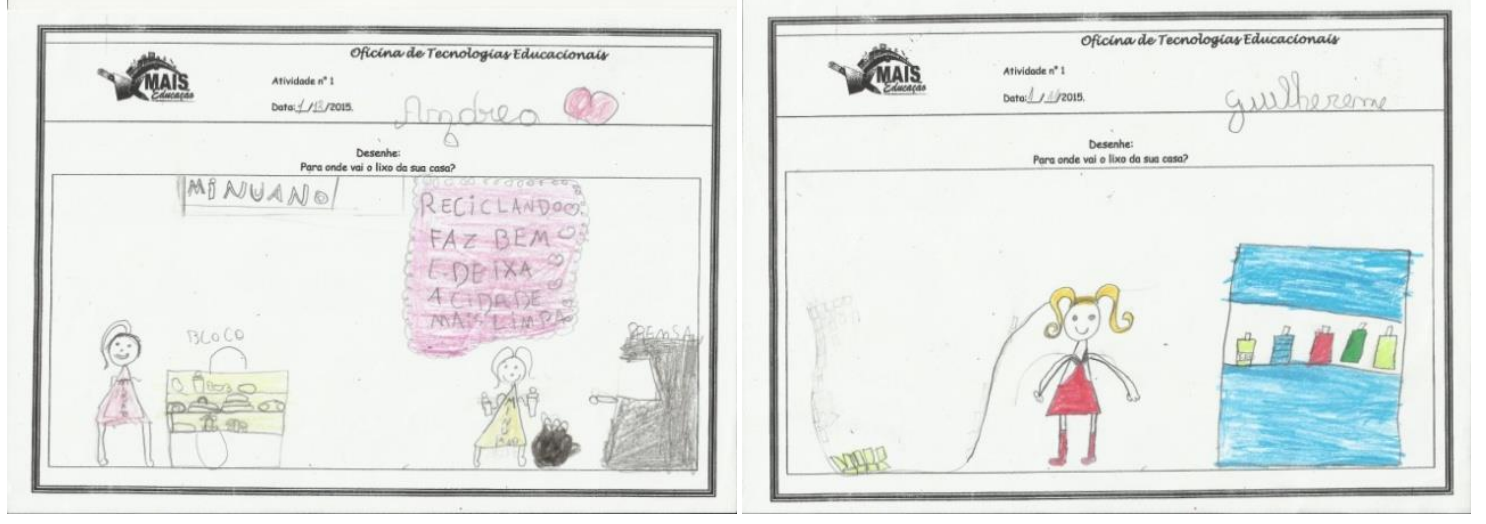

FIGURA 3 - Ilustração dos alunos sobre destino do lixo de suas casas Pesquisa de Campo na rede municipal de ensino de São Gabriel-RS

No desenho acima na imagem 3, a aluna registrou sua observação durante o passeio: os blocos com os materiais já reciclados e a prensa e na imagem 4 a estudante desenhou um saco com alguns materiais e uma prensa, referente ao desenho do saco ela quis ilustrar o processo de triagem dos materiais, que era feitocom sacos.

Dessa forma, observou-se que os alunos tiveram um amadurecimento de ideias comparado ao nosso primeiro dia de atividades com eles, onde realizamos a mesma atividade com a tarefa de ilustrar o destino do lixo de sua casa e a maioria afirmou que o lixo ia para o caminhão de coleta; outros desenharam lixeiras comuns e lixeiras seletivas, dentre outras respostas, sem ter uma noção específica do destino final dos resíduos e seus impactos no meio ambiente.

Estes resultados constam no segundo artigo desta dissertação, com o título: Desenvolvimento de temas CTS em oficinas pedagógicas nos anos iniciais: a educação ambiental como propulsora de uma consciência crítica.

Percebe-se, a importância de utilizar espaços informais fora da sala de aula, alinhando com a proposta do Programa Mais Educação, que identifica a necessidade de explorar outros espaços da cidade para a construção do conhecimento.

Sobre isso Moll (2013) aponta que:

O Programa Mais Educação fomenta e financia atividades propostas, organizadas e coordenadas pela escola e que aconteçam em espaços significativos da vida do bairro e da cidade, estimulando a experiência cultural e civilizatória do cinema, do teatro, do museu, dos parques, das praças, dentre outros, como parte da ação curricular da escola. Tal perspectiva apresenta-se na contramão da segregação em que vivem milhões de crianças, adolescentes e jovens no Brasil, desnaturalizando a compreensão de uma "educação-instituição total". Compreende-se que é necessário, ao 


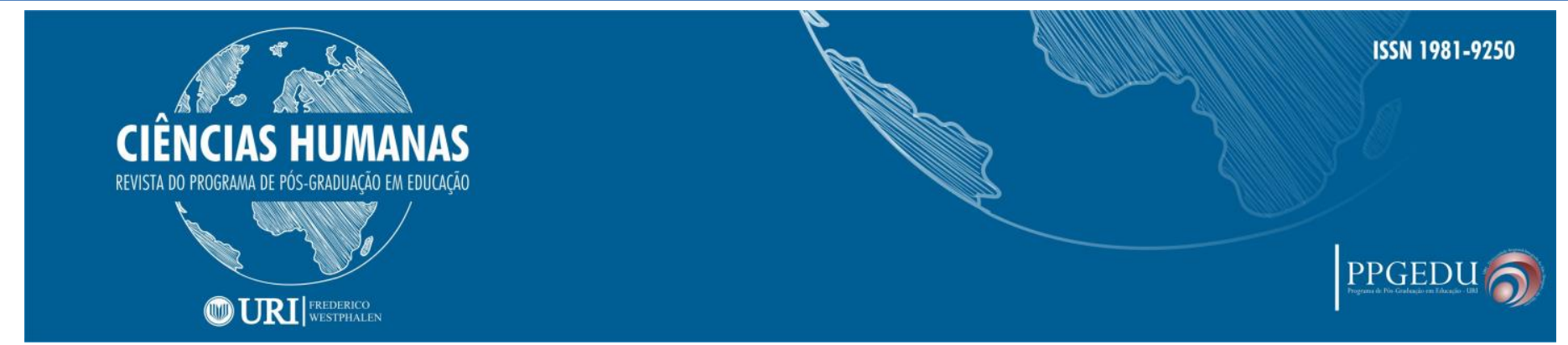

mesmo tempo, qualificar e ampliar as condições da escola em termos de infraestrutura e construir territórios educativos que se expandam a partir e para além dela.(MOLL, 2013, p. 73)

Trevisan e Forsberg (2014) pesquisaram até que ponto a aula de campo em espaços socioambientais tem em seu universo de alargamento aproximações com a abordagem CTS e afirmam em suas conclusões que

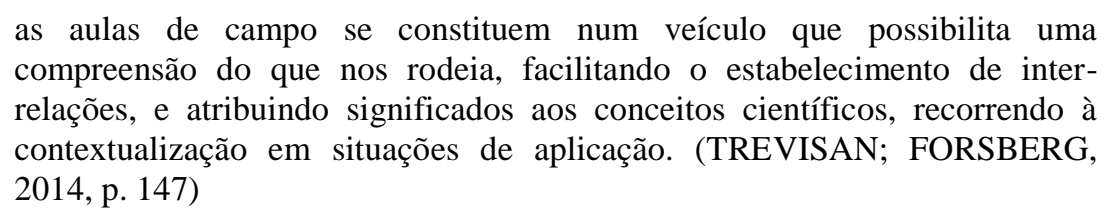

Apresentamos aqui os resultados dos questionários. Este questionário foi composto de oito perguntas abertas, divididas em quatro temas: tratamento do lixo, meio ambiente, saúde e sociedade, sendo duas perguntas para cada tema. O objetivo dessas questões era conhecer as impressões dos estudantes sobre as atividades.

TABELA 2 - Questionário entregue aos alunos?"

Tema

1) Complete:

Tratamento do lixo

Meio Ambiente doenças?

\section{Pergunta}

Quando eu seleciono o lixo:

Quando eu não seleciono o lixo:

1) Se o lixo for descartado em locais inapropriados poderá causar algum problema de saúde?

2) Você acha que o lixo pode ser responsável pelas inundações e alagamentos? Por quê? E pode causar

1) Após descartar o lixo na lixeira comum e na lixeira seletiva, você sabe para onde ele vai?

2) Se o lixo for descartado em locais inapropriados pode causar danos ao meio ambiente?

Quem são os responsáveis pela poluição?

$\begin{array}{ll}\text { Sociedade } & \text { ( ) A prefeitura ( ) Escola ( ) Eu ( ) Não sei } \\ & \text { O que eu faço com meu lixo, quando não tem lixeira por } \\ \text { perto? }\end{array}$

Fonte: Autores. 


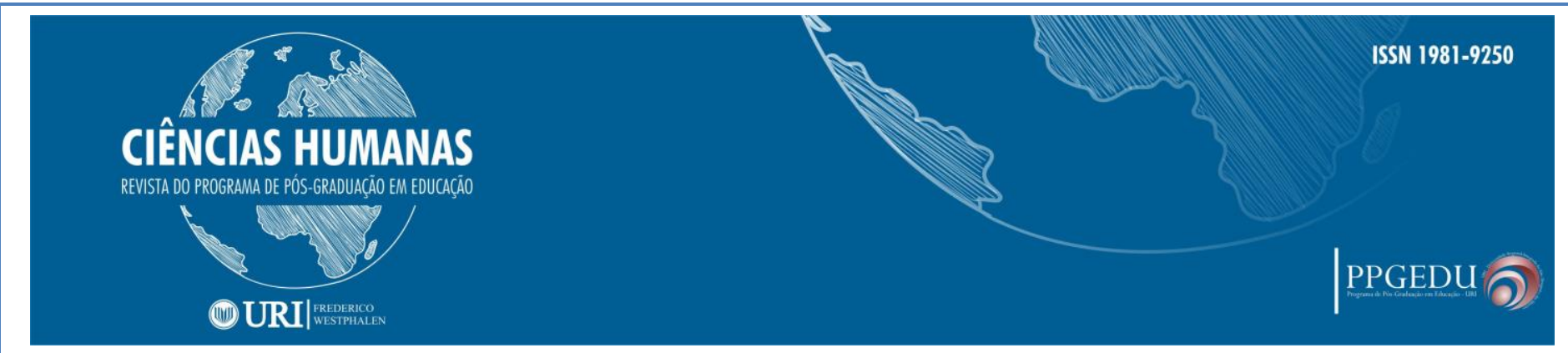

Tratamento do lixo

Quando questionados a respeito do destino do lixo quando ele é selecionado, a palavra mais citada foi "reciclagem" atingindo $70 \%$ (07) das respostas; respostas relacionadas à separação do lixo tiveram $20 \%$ (2) e 10\%(01) mencionaram uma empresa de coleta.

$\mathrm{Na}$ segunda questão, solicitava que os alunos completassem a seguinte frase: "Quando eu não seleciono o lixo...", 70\%(07) responderam que seu destino era o lixão e $30 \%(03)$ responderam que ele ia ser separado. Acredita-se que estes últimos responderam que o lixo era separado, devido a triagem que acontece no antigo aterro antes dos materiais serem encaminhados para o seu destino final na cidade de Santa Maria/RS.

Essas foram questões interessantes, poisse observou que após a visita ao aterro sanitário e a associação de catadores, os estudantes puderam construir seu pensamento sobre os possíveis destinos do lixo. As realidades observadas com certeza influenciarão na tomada de decisões quanto à separação do lixo domiciliar.

Esta visita foi pertinente, pois proporcionou vários momentos de discussão de valores acerca dos impactos do lixo englobando inúmeras questões econômicas, sociais, éticas, ambientais solidarias, de compromisso social, de respeito ao próximo, dentre outras, em acordo com as ideias de Santos e Mortimer (2002):

Será por meio da discussão desses valores que contribuiremos na formação de cidadãos críticos comprometidos com a sociedade. As pessoas, por exemplo, lidam diariamente com dezenas de produtos químicos e têm que decidir qual devem consumir e como fazê-lo. Essa decisão poderia ser tomada levando-se em conta não só a eficiência dos produtos para os fins que se desejam, mas também os seus efeitos sobre a saúde, os seus efeitos ambientais, o seu valor econômico, as questões éticas relacionadas a sua produção e comercialização. (SANTOS; MORTIMER, 2002, p. 5)

Os autores aqui fazem referência a tomada de decisão na compra de produtos, mas sabemos que nas inúmeras situações do dia-a-dia, os alunos precisam ser estimulados a pensar sobre suas atitudes, o simples fato de separar ou não separar o lixo e as consequências, analisando não só a eficiência e praticidade, mas também seus efeitos.

Saúde

Foram usadas duas perguntas abertas para investigar como os alunos relacionam lixo e saúde.

\begin{tabular}{l|l} 
Recebido em: 05/09/2018 & Aceito em: 17/10/2018
\end{tabular}




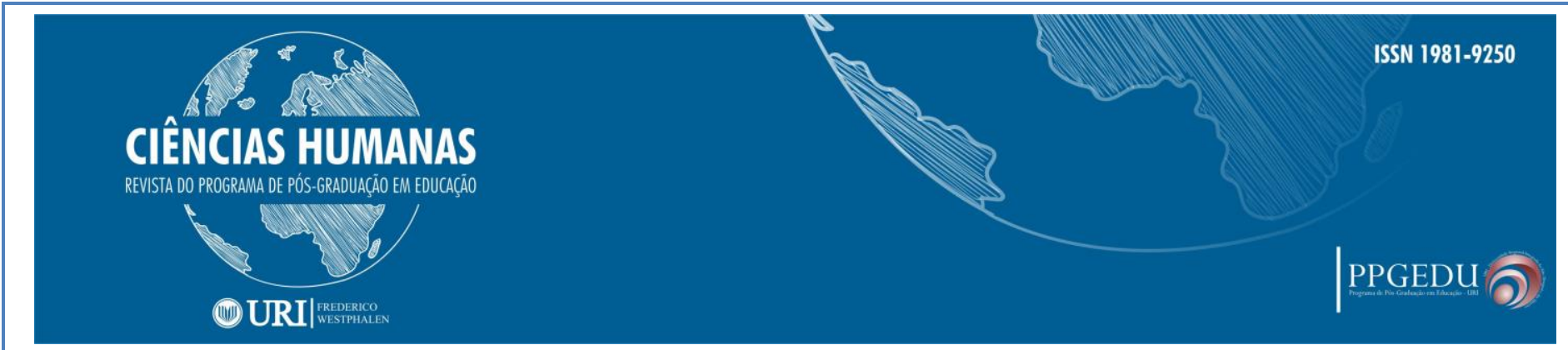

Na primeira pergunta "Se o lixo for descartado em locais inapropriados poderá causar algum problema de saúde? "20\%(02) mencionaram o nome de algumas doenças como: hepatite e verminoses, $80 \%(08)$ tiveram respostas semelhantes a fala dos alunos A e B, como podemos ver, mencionando a presença de micro-organismos.

"Junta lixo e no lixo tem bactérias e elas causam doenças." (Aluno A)

Em relação a pergunta "Você acha que o lixo pode ser responsável pelas inundações e alagamentos? Por quê? E pode causar doenças? "As respostas foram semelhantes a questão anterior, foram bem diretas, 30\%(03) mencionaram respostas semelhantes a do aluno $\mathrm{C}$, apenas identificando que os bueiros enchem, porém sem a justificativa, e associando a água poluída ou suja às doenças; 20\%(02)tiveram respostas como as do aluno $\mathrm{D}$, incompletas e sem uma detalhamento de suas conclusões e por fim $50 \%$ identificaram o entupimento com lixos nas bocas de lobo como responsáveis por alagamentos, reconheceram também a possibilidade do surgimento de doenças.

"Pode, porque os bueiros enchem de água e a água pode tá suja". (Aluno C)

"Porque alaga e a água entra dentro de casa". (Aluno D)

A dissertação de mestrado de Oliveira (2006), se assemelha com nossos resultados, foi pesquisado um grupo de 118 pessoas de 13 a 60 anos, sobre os problemas provocados pelo acúmulo de lixo. Neste estudo, os entrevistados identificaram o fato de atrair animais nocivos e as doenças como um dos problemas. No estudo de Martins, Santos e Leda (2014), os alunos pesquisados, dentre os problemas identificados dentro da sua realidade, mencionaram animais causadores de doenças, enchentes, inundações e lixo descartado em lugar indevido.

O conhecimento de algumas doenças e seus sintomas são temas importantes a serem abordados em aula, visto que a prevenção só acontecerá com o conhecimento das doenças, seus sintomas e meios de transmissão. Os PCN incentivam os professores a estas práticas, sugerindo uma abordagem sobre o "reconhecimento das doenças associadas à falta de higiene no trato com alimentos: intoxicações, verminoses, diarreias e desidratação; medidas simples de prevenção e tratamento" (BRASIL, 1998, p. 77).

Nossos resultados foram interessantes, pois a maioria citou a presença de microorganismos e alguns até mencionaram os nomes de algumas doenças, esta consciência sobre os prejuízos que o lixo pode trazer para o ambiente e para os seres humanos, é importante, pois o conhecimento construído auxiliará nas decisões no dia a dia.

Meio Ambiente

O questionamento sobre o destino do lixo quando colocado na lixeira comum e na lixeira seletiva teve como objetivo investigar se eles reconheciam a importância de usar as lixeiras recicláveis, bem como o destino dos resíduos quando não são separados. Em30\%(03) das respostas não conseguimos resultados esperados, visto que 10\%(01) 


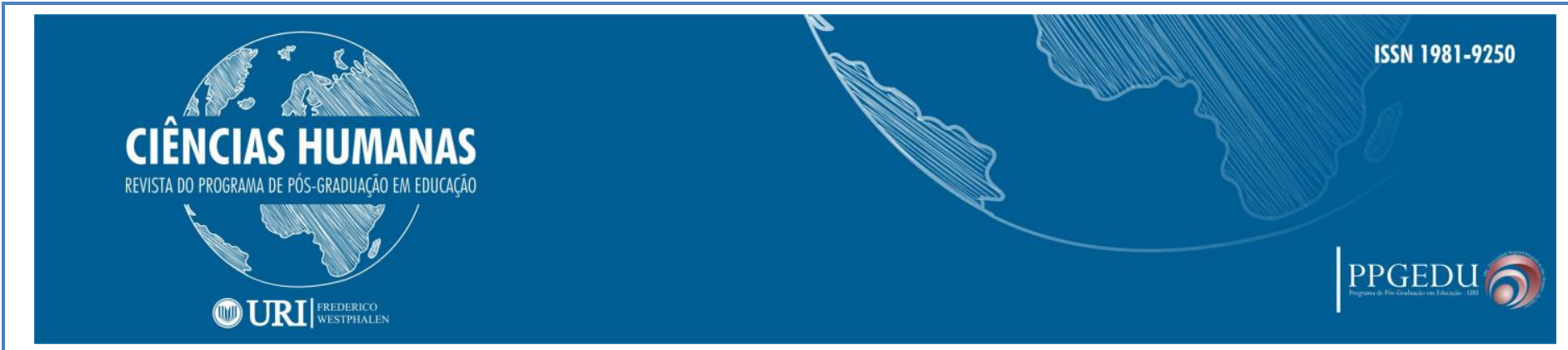

estavam sem justificativa e 20\%(02) incompletas e não adequadas, porém 60\%(06) demonstraram associar a importância da seleção dos resíduos para contribuir com o seu destino final, coleta seletiva e meio ambiente. Como podemos ver na resposta do aluno $\mathrm{F}$.

"A lixeira comum vai para o lixão, a lixeira seletiva vai para o Minuano." (Aluno F)

A segunda questão referente ao Meio ambiente consistia em investigar se os estudantes identificavam algum tipo de dano ao meio ambiente quando o lixo é descartado em locais inapropriados. Em 40\% (04)das respostas os estudantes mencionaram "Poluição e enchentes", 20\% (02) tiveram respostas relacionadas a "inundações", 10\%(01) mencionaram doenças e em 20\%(02) não obtivemos respostas.

Contudo, podemos observar que os estudantes conseguem perceber os efeitos do descarte incorreto do lixo, e a grande maioria compreende que os resíduos passíveis de reciclagem precisam ser separados para terem a possibilidade de serem destinados a coleta seletiva, ou seja ao projeto Minuano em São Gabriel-RS.

Sociedade

Para investigar os aspectos referente ao tema sociedade, utilizamos uma pergunta de marcar e uma pergunta aberta. A primeira se constituía em marcar os responsáveis pela poluição, 70\%(07) identificaram-se como responsáveis, 20\%(02) mencionaram a prefeitura, a escola e si próprio e 10\%(01) responderam que não sabiam.

Chamou a atenção o fato de apenas $20 \%$ (02) mencionar mais de um responsável pela poluição. Poluidor é considerado "a pessoa física ou jurídica, de direito público ou privado, responsável direta ou indiretamente por atividade causadora de degradação ambiental" (BRASIL, 1981, p. 6).

O fato dos estudantes ficarem confusos sobre os agentes poluidores, é que muitas vezes o conteúdo é ministrado aos alunos de forma compartimentada, sem uma contextualização.

A educação CTS parte dos contextos para os conteúdos e sugere uma abordagem interdisciplinar em que os estudantes possam entender a Ciência como em aporte para compreensão das situações do dia a dia. Moraes (1997, p. 174), concorda e acredita que a educação deve preparar o aluno "para que seja capaz de compreender as consequências globais de seus atos individuais, de conceber prioridades e assumir as formas de solidariedade que constituem o destino da espécie"

Em relação a segunda pergunta, que questionava qual o posicionamento do estudante quando tinha algum lixo em mãos e não havia lixeira por perto, as respostas ficaram dentro do esperado, 90\%(09) informaram que guardavam até encontrar uma lixeira e apenas 10\%(01) relataram que jogavam na rua. 


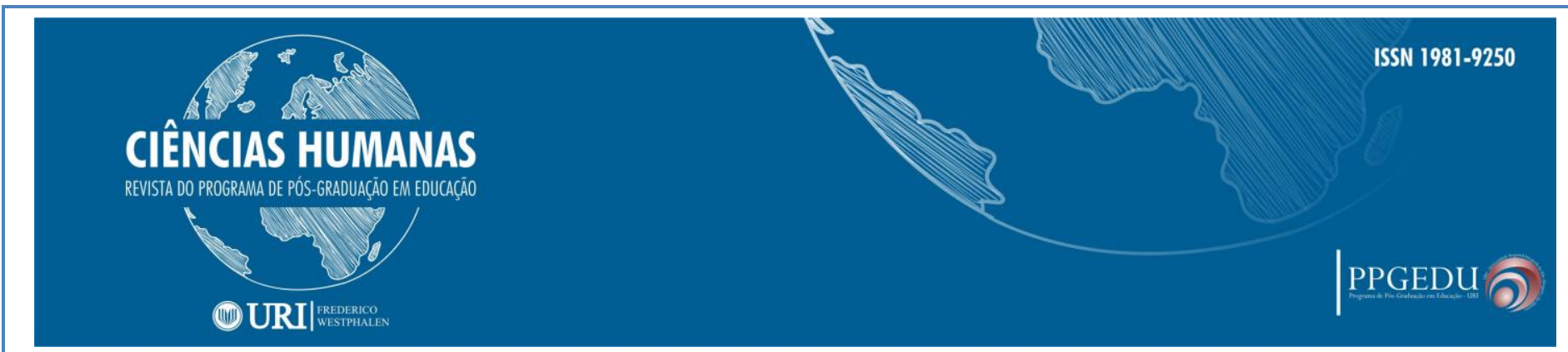

Este resultado mostra que os estudantes estão conscientes que pequenas atitudes são necessárias para cuidar do meio em que vivemos. Em concordância com a nossa amostra Andrade e Musse (2014) pesquisaram a percepção de alunos do Ensino Fundamental I e sua relação com a preservação do meio ambiente e encontrou o mesmo tipo de conceito, sendo $61 \%$ se referiram a não jogar lixo no chão como estratégia para cuidar do meio ambiente.

Ainda no eixo temático sociedade, foi trabalhada a oficina com o tema reciclagem, no primeiro momento, na problematização foram abordadas algumas questões sobre o plástico, tais como: de onde vem o plástico? De que forma o mau uso do plástico prejudica o meio ambiente? O que precisamos fazer para usarmos o plástico sem destruir e prejudicar o meio ambiente? Vocês já ouviram falar em reciclagem? O que é? Quanto tempo o plástico demora para desaparecer do meio ambiente? De que forma o plástico pode ser reciclado?

$\mathrm{Na}$ organização do conhecimento, os alunos assistiram a um vídeo sobre a origem do plástico e puderam compreender os processos realizados para a fabricação do plástico bem como a importância de cuidar do meio ambiente, por meio da reutilização de plástico.

$\mathrm{Na}$ aplicação do conhecimento, os estudantes vivenciaram a experiência de fabricação de brinquedos com garrafas PET reciclável.

Ao final desta pesquisa, os alunos fizeram um vídeo ${ }^{\mathbf{1 0}}$ informativo sobre a importância de separar o lixo e observar os dias e horários da coleta seletiva em São Gabriel/RS.

\section{CONSIDERAÇÕES FINAIS}

Neste trabalho relatamos os resultados da aplicação de oficinas no Programa Mais Educação com uma abordagem CTS, estruturadas nos três momentos pedagógicos de Delizoicov e Angotti (1992). Separamos as oficinas por temáticas: Meio ambiente, saúde e sociedade.

Durante as oficinas, as atividades propostas fizeram os estudantes refletir sobre aspectos políticos, econômicos, conhecimentos científicos e tecnológicos. A metodologia dos três momentos pedagógicos foi importante, pois a problematização favoreceu o desenvolvimento de conhecimentos científicos por estarem interligados ao contexto dos estudantes.

O uso da fotografia propiciou o desenvolvimento de valores, atitudes e reflexão para uma consciência crítica, pois, por meio delas, os estudantes conseguiram perceber o meio ambiente com um olhar diferenciado. Observamos em vários momentos que os

\footnotetext{
${ }^{10}$ Disponível em: https://youtu.be/pQSoC2KS2Cc.
} 


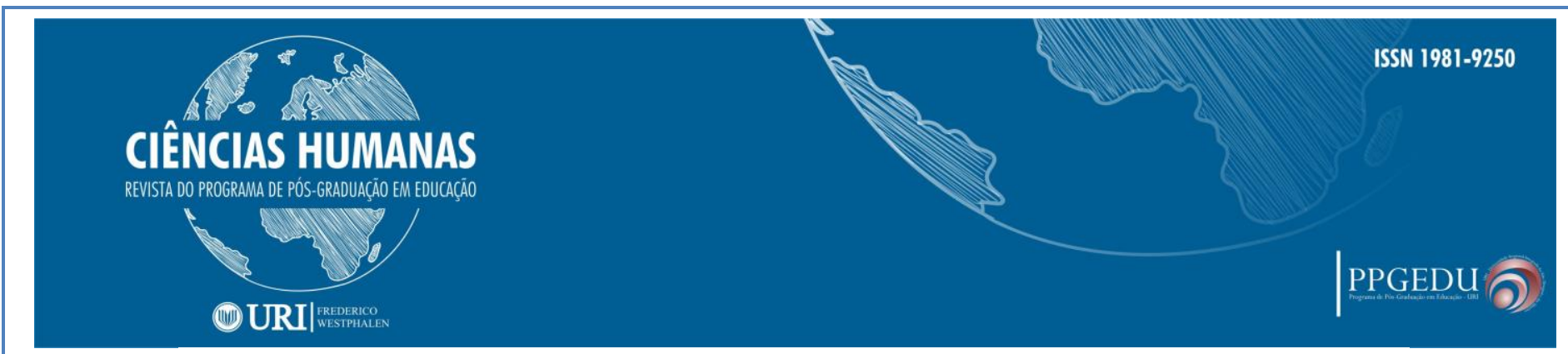

estudantes se sentiram responsáveis pelo ambiente e identificaram a necessidade de uma mudança de atitudes. Reconheceram também a necessidade de envolver a comunidade na busca de soluções para resolver problemas locais, dessa forma ficaram motivados para a produção do recurso audiovisual sobre a coleta seletiva de São Gabriel expandindo os conceitos construídos nas oficinas.

Em várias etapas da pesquisa, percebemos proximidades entre os pressupostos da educação integral e a abordagem CTS. Destacamos aqui algumas premissas que constituem a educação integral: o direito a uma educação de qualidade com mais tempo para aprendizagens significativas, compreensão da cidade como espaço educador, espaços escolares e não escolares e a reestruturação do Projeto Político Pedagógico contemplando princípios e ações para uma formação mais humana e integral (BRASIL, 2013). ${ }^{11}$

A educação CTS, atua com uma abordagem de formação para cidadania, tem como "objetivo do desenvolvimento da capacidade de tomada de decisão na sociedade cientifica e tecnológica e o desenvolvimento de valores" (AULER, 2011, p. 23).

Dessa forma, observamos que as duas se complementam, a educação integral principalmente por proporcionar esse tempo a mais na escola para discussões de temas pertinentes a sociedade e aprendizagens significativas. Bem como Krasilchik e Marandino (2004) afirmam que,

para participar efetivamente de uma sociedade é necessário que o indivíduo tenha sensibilidade para identificar questões, compreender o seu significado, as limitações e perspectivas dos problemas identificados e assim ficar capacitado a tomar decisões fundamentadas de forma responsável e coerente com seus valores e posturas éticas (KRASILCHIK; MARANDINO, 2004, p. $34)$.

Acreditamos que as oficinas com abordagem CTS no Programa Mais Educação, são estratégias enriquecedoras para o desenvolvimento de uma série de habilidades almejadas na perspectiva de educação integral, principalmente no sentido de reconhecer o estudante como sujeito de direito e agente transformador de realidade, vislumbrando melhorar o processo educacional em todos os aspectos, atribuindo valor e significado para vida.

\footnotetext{
11،“A Fundação Estadual de Proteção Ambiental Henrique Luis Roessler* - FEPAM,é a instituição responsável pelo licenciamento ambiental** no Rio Grande do Sul. Desde 1999, a FEPAM é vinculada à Secretaria Estadual do Meio Ambiente - SEMA. " Disponível em: http://www.fepam.rs.gov.br/

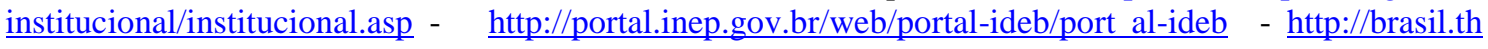
ebeehive.org/content/1842/5004. Disponível em: http://www.planetavivo-rs.org.br/
}

\begin{tabular}{l|c|c|c}
\hline Rev. Ciências Humanas & Frederico Westphalen, RS & Pg. 118 - 142 & mai./ago. 2018 \\
\hline
\end{tabular}




\section{REFERENCIAS}

ANDRADE, F. T.; NSO MUSSE. Análise da percepção ambiental de alunos do ensino fundamental de uma escola pública de Martins-RN. Anais V SETEPE V, 1, 2015, ISSN 2359-2014. Acesso em: 01/03/2-17 Disponível em: http://www.editorarealize.com .br/revistas/setepe/trabalhos/Modalidade_1datahora_24_09_2014_19_24_35_idinscrito_ 123 bfc61f66adf70998ed46a00a7c211212.pdf

AULER. D. Enfoque Ciência-Tecnologia-Sociedade: Pressupostos para o contexto brasileiro. Ciência e Ensino, v.1, n. especial, p. 1-20, 2007.

ALBUQUERQUE, Daniel Silva de. O que é um PEV (posto de entrega voluntária) e onde pode ser encontrado. Acesso em: 02/03/2017, disponível em:

http://brasil.thebeehive.org/content/1842/5004

BERNARDO, José Roberto da Rocha. A construção de estratégias para uma abordagem do tema energia à luz do enfoque ciência-tecnologia-sociedade (CTS) junto a professores de física do ensino médio. Tese (Doutorado em Ensino de Biociências e Saúde) - Instituto Oswaldo Cruz, Fundação Oswaldo Cruz, Rio de Janeiro, 2008.

BRANDAO, C.R; STRECK, D.R. (Org.). Pesquisa participante: o saber da partilha. Aparecida, SP: Ideias\& Letras, 2006. p. 295.

BRASIL. Caminhos para elaborar uma proposta de educação integral em jornada ampliada: como ampliar tempos, espaços e oportunidades educativas para crianças, adolescentes e jovens aprenderem. Brasília, 2013a.

BRASIL, Lei de Diretrizes e Bases. Lei no 9.394/96, de 20 de dezembro de 1996.

BRASIL. Manual Operacional de Educação Integral. Brasília: MEC/SEB/DICEI, 2013b. Acesso em: dezembro. 2016. Disponível em: <http://portal.mec.gov.br/ index.php?option=com docman \&view=download \&alias=14458-manual-maiseducacao-2013-final-171013-2-pdf\&Itemid=30192>.

BRASIL. Manual Operacional de Educação Integral. Brasília: MEC/SEB/DICEI, 2014. Acesso em: dezembro. 2016. Disponível em: http://anexos.datalegis.inf.br/ arquivos/1240866.pdf

BRASIL, Ministério da Educação. Secretaria de Educação Básica. Educação Integral: texto referência para o debate nacional. Brasília, 2013.

BRASIL. Ministério do Meio Ambiente. MEC. Política Nacional do Meio Ambiente.Lei No . 6938/81. Acesso em: 01/03/2017. Disponível em: http://www.planalto.gov.br/ccivil_03/LEIS/L6938.htm 
BRASIL. Secretaria de Educação Fundamental. Parâmetros Curriculares Nacionais: Introdução. Brasília: MEC/SEF, 1998.

BRASIL. Programa Mais Educação: passo a passo. Brasília, 2013b.

DELIZOICOV, D.; ANGOTTI, J.A. Metodologia do Ensino de ciências. 2 ed. São Paulo: Cortez,1992.

GIOLO. Jaime. Educação de tempo integral: Resgatando elementos históricos e conceituais para o debate. In: MOLL, Jaqueline. Caminhos da educação Integral no Brasil: direito a outros tempos e espaços educativos. Porto Alegre: Penso, 2012.p. 94105.

HENZ, Celso Ilgo. Paulo Freire e educação integral: cinco dimensões para (re) humanizar a educação. In: MOLL, Jaqueline. Caminhos da educação Integral no Brasil: direito a outros tempos e espaços educativos. Porto Alegre: Penso, 2012.p. 8293.

HERREID, C.F. What Makes a Good Case? Journal of College Science Teaching, v. 27, n.3, p. 163-169, 1998.

KRASILCHIK, Myriam; MARANDINO, Martha. Ensino de ciências e cidadania. São Paulo: Moderna, 2004.

MARTINS, Isabel P.; PAIXÃO, Maria de Fátima. Perspectivas atuais CiênciaTecnologia - Sociedade no ensino e na investigação em educação em ciência. IN: SANTOS, W.L.P; AULER, Décio. CTS e educação científica: desafios, tendências e resultados de pesquisa. Brasília: Editora Universidade de Brasília, 2011. p. 135-160.

MARTINS, Wania Elisa; SANTOS, Thaynara Nascimento dos; LEDA, Luciana Ribeiro. Aplicação da metodologia da problematização na alfabetização ecológica: o desenvolvimento de uma nova percepção sustentável. Revista da SBEnBio, n. 7, Out 2014. Acesso em 01/03/2017. Disponível em: <http://www.sbenbio.org.br/wordpress /wp-content/uploads/2014/11/R0628-1.pdf $>$.

MOLL, Jaqueline. A construção da educação integral no Brasil: aportes do Programa Mais Educação. In: COELHO, Ligia Martha C. da Costa. Educação integral: História, políticas e práticas. Rio de Janeiro. Rovelle, 2013. p. 69-83.

MOLL, Jaqueline. O PNE e a educação integral desafios da escola de tempo completo e formação integral. IN: Retratos da Escola. Escola de Formação da Confederação Nacional dos Trabalhadores em Educação (esforce) - v.8, n15, jul./dez.2014. Brasília: CNTE, 2007. p. 369-380. 


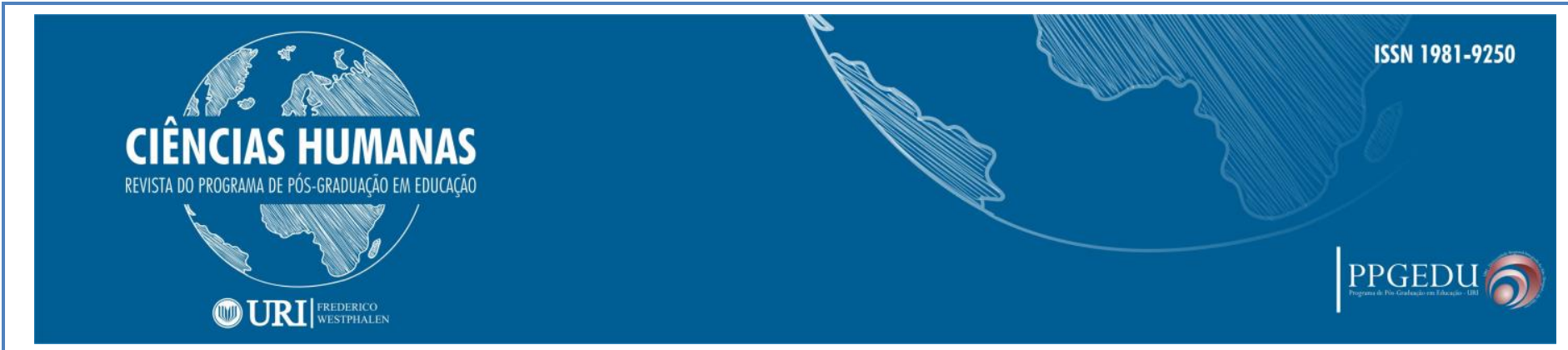

MORAES, M. C. O paradigma Educacional emergente. $13^{\text {a }}$ ed. Campinas, São Paulo: Papirus, 1997.

OLIVEIRA, Nilza Aparecida da Silva. A percepção dos resíduos sólidos (lixo) de origem domiciliar, no Bairro Cajuru-Curitiba-PR: um olhar reflexivo a partir da educação ambiental. Dissertação (Mestrado em Geografia, Setor de Ciências da Terra) Universidade Federal do Paraná. Curitiba, 2006.

SANTOS, Wildson Luiz Pereira. Significados da educação científica com enfoque CTS. In: SANTOS, W.L.P; AULER, Décio. CTS e educação científica: desafios, tendências e resultados de pesquisa. Brasília: Editora Universidade de Brasília, 2011. p. 21-39.

SANTOS, Wildson Luiz Pereira; MORTIMER. E.F. Abordagem de aspectos sociocientíficos em aulas de ciências: possibilidades e limitações. Investigações em Ensino de Ciências, v. 14, n 2, p. 1-23, 2002.

SANTOS, Wildson Luiz Pereira; AULER, Décio. CTS e educação científica: desafios, tendências e resultados de pesquisa. Brasília: Editora Universidade de Brasília, 2011. p. 323-345.

SILVA, Osmar Benedito; OLIVEIRA, Jane Raquel Silva; QUEIROZ, Salete Linhares. Abordagem CTS no Ensino Médio: estudo de caso com enfoque sociocientífico. IN: SANTOS, Wildson Luiz Pereira; AULER, Décio. CTS e educação científica: desafios, tendências e resultados de pesquisa. Brasília: Editora Universidade de Brasília, 2011. p . 323-345.

TRAJBER, Rachel. Educação Integral em escolas sustentáveis: Políticas públicas para os desafios da contemporaneidade. IN: MOLL, Jaqueline. Caminhos da educação Integral no Brasil: direito a outros tempos e espaços educativos. Porto Alegre: Penso, 2012. p. 172-188.

TREVISAN, Inês; FORSBERG, Maria Clara Silva. Aulas de campo no ensino de ciências e biologia: aproximações com a abordagem ciência, tecnologia e sociedade (CTS). Scientia Amazônia, v. 3, n.1, 138-148, 2014. 